\title{
Review
}

Heidi Olzscha*

\section{Posttranslational modifications and proteinopathies: how guardians of the proteome are defeated}

https://doi.org/10.1515/hsz-2018-0458

Received December 10, 2018; accepted April 13, 2019; previously published online April 18, 2019

\begin{abstract}
Protein folding is one of the fundamental processes in life and therefore needs to be tightly regulated. Many cellular quality control systems are in place to ensure that proteostasis is optimally adjusted for a changing environment, facilitating protein folding, translocation and degradation. These systems include the molecular chaperones and the major protein degradation systems, namely the ubiquitin proteasome system and autophagy. However, the capacity of the quality control systems can be exhausted and protein misfolding and aggregation, including the formation of amyloids, can occur as a result of ageing, mutations or exogenous influences. There are many known diseases in which protein misfolding and aggregation can be the underlying cause of the pathological condition; these are referred to as proteinopathies. Over the last decade, it has become clear that posttranslational modifications can govern and modulate protein folding, and that aberrant posttranslational modifications can cause or contribute to proteinopathies. This review provides an overview of protein folding and misfolding and the role of the major protein quality control systems. It focusses on different posttranslational modifications and gives examples of how these posttranslational modifications can alter protein folding and cause or accompany proteinopathies.
\end{abstract}

Keywords: acetylation; aggregation; amyloid; neurodegenerative disease; protein folding; ubiquitin proteasome system.

\section{Introduction}

The importance of proteins is underlined by their name,

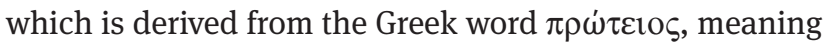
'primary' or 'first'. Folding of individual proteins and the integrity of the whole proteome is crucial to most cellular processes, including cell growth and survival. Mutations, posttranslational modifications and exogenous factors such as thermal stress or artificial compounds can alter the folding and three-dimensional (3D) structure of proteins and therefore their function, resulting in disturbed cellular processes. Cells have developed several mechanisms to protect themselves against protein misfolding, to maintain the balance of protein biogenesis, folding and degradation and to adjust these processes to changing conditions. If protein homeostasis, also named proteostasis, fails, protein misfolding can occur; accumulation of these misfolded proteins into aggregates can culminate in the formation of poorly soluble amyloid or amyloid-like protein aggregates. Protein quality control systems such as the ubiquitin proteasome system (UPS), autophagy or the system of molecular chaperones monitor and control the status of the proteome and ensure that homeostasis is maintained.

It has become increasingly evident in recent years that protein misfolding and proteinopathies which are also termed proteopathies or protein misfolding diseases (PMDs), do not only manifest in well-known neurodegenerative diseases, but also play a role in the initiation and progression of metabolic and neoplastic diseases, including diabetes and haematological malignancies.

Posttranslational modifications (PTMs) are modifications of proteins attached after their biosynthesis and can change protein folding as well as intra- and intermolecular interactions. This review will focus on altered proteostatic conditions, the instability of proteins in response to posttranslational modifications and exogenous influences, including drug treatment that targets molecules in the different protein quality control apparatus and modulate the PTM pattern on proteins. Different proteinopathies are 
given as examples of how PTMs can affect misfolding and the underlying pathophysiology.

\section{Protein folding, misfolding and aggregation}

Protein folding can be defined as a process by which a protein reaches a 3D structure, implying a collapse of the nascent protein chain into a compact structure. Usually, protein folding in living systems, i.e. cells, culminates in a native protein that can fulfil its physiological function. Importantly, proteins can assemble into functional structures and supra-structures, which can be distinguished from protein aggregates. Protein folding is a complex process dependent on many factors, including the length of the protein, number and sub-structure of its domains and presence or absence of intrinsically disordered regions (IDRs). These are inherent determinants in the amino acid sequence of a given protein and therefore in the genome; the seminal experiments by Christian Anfinsen showed that they determine folding and refolding of a protein in vitro (Anfinsen et al., 1961). However, there are additional determinants and confounders that dictate the folding of proteins in cells. One example of these determinants is the individual space of a given protein, whereby molecular crowding can reduce the degrees of freedom a protein has to fold and move within the 3D space (van den Berg et al., 1999). Other examples include the different cellular context between and within individuals as well as different expression in various tissues (Arndt et al., 2010; Gidalevitz et al., 2011). The possibility of misfolding and aggregation of proteins can increase as a result of limited proteostatic capacity in cells with a high protein synthesis rate, for instance in plasma cells. Posttranslational modifications (PTMs) can modulate the protein structure leading to locally alternative conformations and eventually misfolding and aggregation (see section above for more details) (Nussinov et al., 2012). Native protein conformations often correlate with the most favourable and stable thermodynamic structures under physiological conditions (Dobson and Ellis, 1998; Knowles et al., 2014). One would assume that due to the high absolute number of possible conformations of a protein, folding and assembly may take a very long time; however, once translated, proteins fold spontaneously within a diffusional search on a free energy surface (Knowles et al., 2014). Weak interactions that occur progressively during folding can restrict the available conformational space and therefore the degrees of freedom.
The restrictions of the available conformational space can eliminate certain off-pathway possibilities and explain to some extent the Levinthal paradox (Levinthal, 1969; Rooman et al., 2002). The fact that high kinetic barriers may have to be crossed at this point allows partially folded states to occur, implying that the free energy surface is 'rugged' (Jahn and Radford, 2005). The partially folded polypeptide chain and accompanying fluctuations in its conformation also facilitate interactions from linear further distant amino acid residues and establish contacts. The hydrophobic effect can be seen as a driving force for a protein to collapse and fold in an aqueous cellular environment. A number of further difficulties occur during these processes in the cells: many proteins, especially those with a globular structure, contain IDRs and lack a final 3D structure. That could be a permanent feature of a protein; however, a protein may only contain IDRs when it is not associated with its specific molecular target (Uversky and Dunker, 2010; Wright and Dyson, 2015). Proteins were evolutionary selected to have a low aggregation propensity, for instance, they usually have a low proportion of hydrophobic amino acid residues, a high net charge and higher frequencies of proline residues (Lise and Jones, 2005; Uemura et al., 2018). In fact, other studies have shown that alternating patterns of hydrophilic and hydrophobic amino acid residues were avoided during evolution, whenever possible. An in silico analysis of 250514 protein sequences (79 708 024 residues) for many possible binary patterns of polar and non-polar amino acid residues revealed that alternating patterns occur significantly less often than other patterns with similar compositions (Broome and Hecht, 2000).

Different opinions can be found in the literature about what it actually means when a protein is misfolded. The prefix 'mis-' means something is bad, wrong or erroneous. This would be a subjective criterion for the state of a protein, as sometimes proteins are not in the native state and may be beneficial for the cell (e.g. proteins with IDRs), depending on the circumstances or interactors. Beyond the structural aspect which is associated with the term 'misfolded', the physiological and functional aspect is also important. A narrower definition of protein misfolding would be 'a structurally aberrant state with no physiological function'. Protein misfolding can lead to aggregation, the accumulation of two or more misfolded proteins that interact in a non-functional manner. The protein aggregates are usually held together with non-covalent bonds, meaning that the aggregation process is in theory reversible. However, certain highly organised 
aggregated structures, the amyloid fibres, have a very low free energy and are thermodynamically extremely stable.

Further difficulties can occur in cells compared to proteins solubilised in a test tube. For instance, the interaction with binding partners, for which the proteins have to obtain a certain flexibility, decreases their thermodynamic stability. Additional complexity is added to the process in that nascent chains are emerging in vivo, which can only be partially folded. Nascent chains emerge in approximately $15-74 \mathrm{~s}$ for a 300 amino acid-containing protein in eukaryotes, but cannot completely fold into the 3D structure, only secondary structure elements can be folded (Etchells and Hartl, 2004; Lu and Deutsch, 2005). These nascent polypeptide chains expose hydrophobic amino acid residues which are usually buried inside a protein and build its core, with possible intra- but also intermolecular hydrophobic interactions that facilitate misfolding and aggregation. Nascent chains, which can occur in close proximity to each other on polysomes, are in danger of interacting due to their exposed hydrophobic residues. A study of the spatial alignment of polysomes revealed a staggered organization of ribosomes along the mRNA and gives a good example how disfavoured interaction could be avoided in cells (Brandt et al., 2009). In a similar vein, the folding efficiency of multidomain proteins can be severely perturbed by alterations in ribosome-mediated translational attenuation (Zhang et al., 2009). In fact, it is assumed that cotranslational folding is limited by the speed of the gradual extrusion of the nascent peptide which imposes conformational restraints on the emerging protein (Zhang and Ignatova, 2011). In order to facilitate protein folding in this crucial time of emerging from the ribosome, molecular chaperones can interact with the nascent chains and prevent protein misfolding (Deuerling and Bukau, 2004), see also the section 'Protective mechanisms and quality control' and Figure 2. In addition, damage of proteins, for instance, by high energy radiation and oxidative stress can alter protein folding or refolding (Cao et al., 2014). Consequently, changing of PTMs via endogenous pathways or forced via exogenous influences can lead to different protein folds, some that are beneficial and are part of the functional spectrum of proteins, and some that are devastating and kill the biological function.

Similar to the term 'misfolding', 'aggregation' can have different meanings in the context of proteins and different definitions are in use. Derived from the Latin word 'aggregare', it means 'to add on'. Protein aggregation means the accumulation or clumping of misfolded proteins and can occur intracellularly or extracellularly in organisms.
However, there are cases were functional aggregates are being built (Chiti and Dobson, 2006; Jackson and Hewitt, 2017). Cellular aggregates often consist of one protein species, with inclusions of other aggregation-prone molecules (Olzscha et al., 2011). Different species of aggregates can emerge over time, depending on the specific protein, the histological context, exogenous factors and the age of the organism. Generally, it can be distinguished between three different types of aggregates, the oligomers, amorphous aggregates and amyloid aggregates. It is very common that the process of aggregation leads to the formation of amorphous structures, and often oligomeric species can precede the formation of these structures (Hong et al., 2011). Aggregation can also culminate in the formation of highly ordered structures, the amyloid fibrils. The term 'amyloid' means 'starch-like' as it shows a reaction with Lugol's iodine similar to starch and was coined by the German botanist Matthias Schleiden in a biological context in 1838. Rudolph Virchow integrated it in the medical terminology in 1854, assuming that cerebral corpora amylacea could be considered identical to starch (Kyle, 2001; Buxbaum and Linke, 2012).

Many, if not all, proteins can form amyloid structures under appropriate conditions. In a physiological milieu, only some proteins form amyloid fibrils. A common structural element, and still the gold standard to determine whether a biological compound is amyloid or not, are $\beta$-strands running perpendicular to the fibril axis seen as the cross- $\beta$ pattern obtained in X-ray fibre diffraction (Sunde et al., 1997; Eisenberg and Jucker, 2012; Fitzpatrick et al., 2013). Further characteristics of amyloid are the typical fibrillary morphology seen in electron microscopy, the affinity for certain diagnostic dyes such as Congo red, already used by Virchow, display of a characteristic apple-green birefringence in polarised light and a remarkable stability against degradation and solubilisation in detergents.

Unlike the native state of a protein, which is stabilised by intramolecular interactions, amyloid forming proteins are dominated by intermolecular interactions, especially when the concentration increases. Those proteins that are supersaturated with high cellular concentration relative to their solubility are most likely to aggregate and a metastable sub-proteome can be formed, ready to initiate aggregation when cellular conditions change (Ciryam et al., 2013). There are also cases known, where early aggregates can build distinct structures, including defined annular structures (Lashuel et al., 2002). Many hypotheses have been proposed to explain the cytotoxicity of protein aggregation (Figure 1) (Lahortiga and Cox, 2018), not necessarily excluding each other. Besides the 


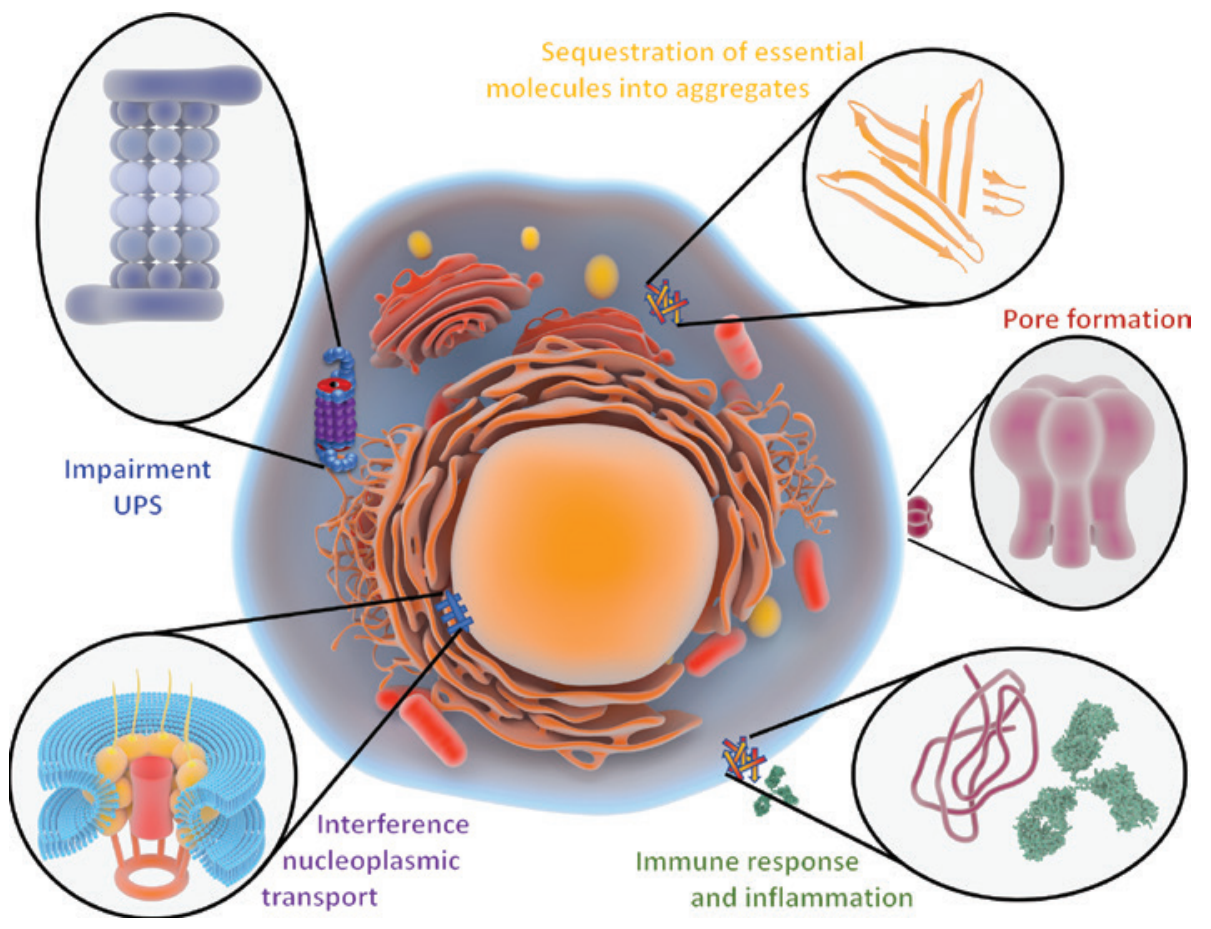

Figure 1: Hypotheses explaining observed cytotoxicity of misfolded proteins in mammalian cells.

Five different hypotheses are offered and cellular substructures shown where the main events take place: sequestration of proteins in the cytoplasm, impairment of the UPS in the cytoplasm and nucleus, formation of pore structures in cellular membranes, intervention of misfolded proteins with nuclear transport processes and extracellular immune recognition of misfolded species with subsequent inflammatory response. The hypotheses do not exclude each other and can vary between different proteinopathies, involved PTMs, tissues and cell types.

loss of function of an aggregating protein, other hypotheses include the formation of pores (Lasagna-Reeves et al., 2011), sequestration of other proteins into aggregates (Olzscha et al., 2011), impeding nuclear transport (Woerner et al., 2016), impairment of important quality control mechanisms (Bence et al., 2001) and immunological reactions against misfolded proteins (Halle et al., 2008). Interestingly, the proteins which form amyloid structures under physiological conditions, do not have many structural features in common. Sections below provide insight into some diseases associated with aggregation and the underlying mechanisms of protein misfolding.

\section{Protective mechanisms and protein quality control}

Organisms have developed a variety of mechanisms to encounter protein misfolding and aggregation and to ensure that proteostasis, a portmanteau of the words protein and homeostasis, is maintained. Proteostasis is the control, regulation and maintenance of concentration, conformation, localisation and interactions of individual proteins within all proteins, the proteome. Organisms and cells can thereby alter the proteome and can even reset the marks of proteostasis in that the physiological targets are met. Therefore, proteostasis influences specific cellular functions and enables differentiated cells and tissues to adapt to physiological changes, environmental changes or ageing. Accordingly, protein quality control mechanisms and systems ensure that the quality of proteins is monitored and maintained (Balch et al., 2008; Balchin et al., 2016). Protein synthesis, folding, PTMs, localisation, transport and degradation can be modulated, and protein quality control systems can interfere with these crucial steps in the life of a protein. Despite the fact that protein sequences were selected against misfolding and aggregation during evolution (see also section above) (Broome and Hecht, 2000; Chiti et al., 2003; Pawar et al., 2005), they may occur in extreme environments, in the presence of mutations or during ageing. Cells have developed different lines of defence to counteract the inherent tendency of proteins to aggregate. An overview of the different systems and how they are connected to each other is given in Figure 2. 


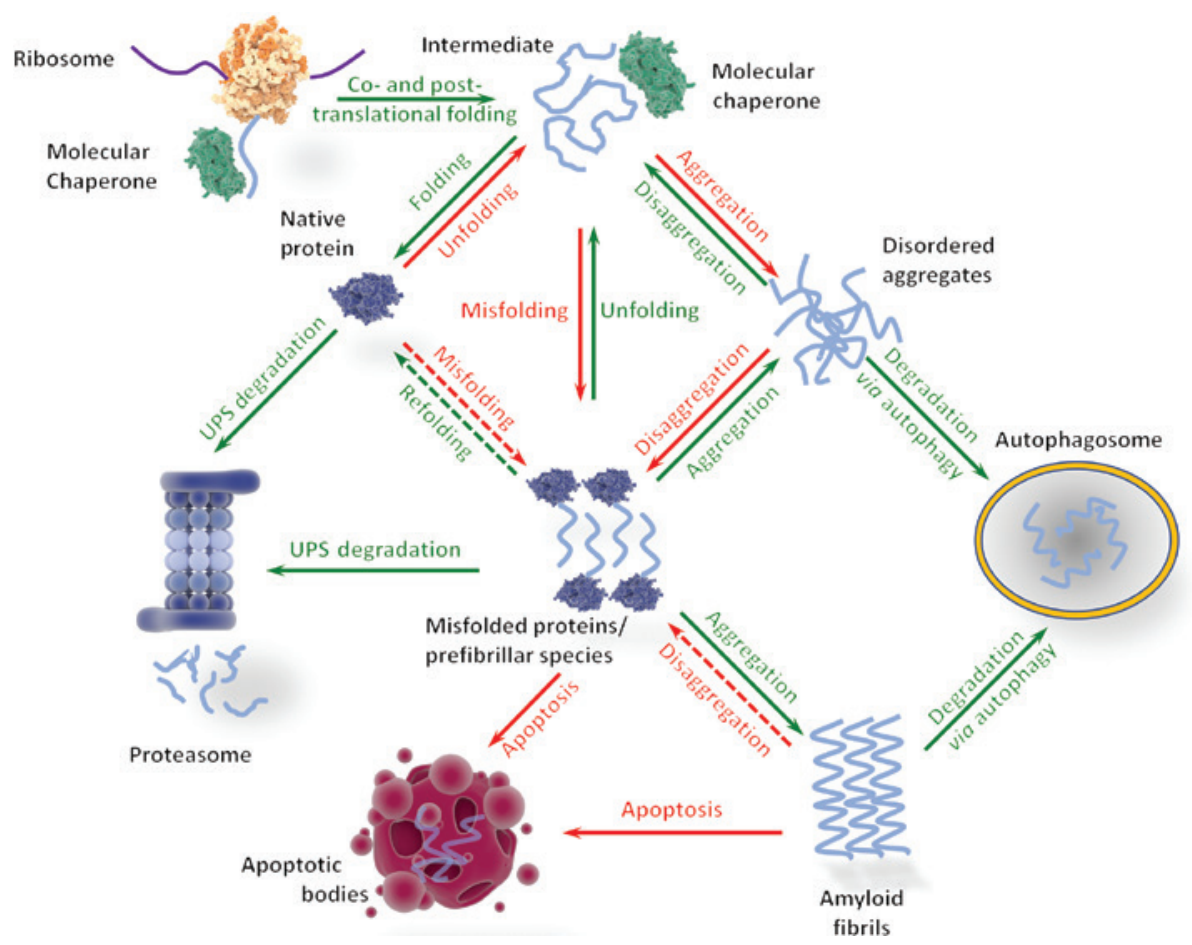

Figure 2: Overview of protein folding and misfolding, aggregation and major protein quality control systems.

Molecular chaperones help nascent proteins and unfolded proteins to fold and reach their native structure. Proteins can misfold under certain circumstances, e.g. in a changing environment, due to mutations or aberrant PTMs. These misfolded species can form disordered aggregates, but also prefibrillar species and/or oligomers; misfolding can culminate in the formation of highly ordered amyloid aggregates. The ubiquitin proteasome system (UPS) and autophagosomes can degrade misfolded proteins and aggregates. If, however, the protein quality control systems fail, misfolded species will accumulate, and cells will eventually undergo apoptosis. Green arrows indicate beneficial events where protein quality control can help to restore proteostasis, red arrows mark deleterious events for the cell. It is debatable, whether the formation of aggregates out of oligomers and prefibrillar species is beneficial for cells.

\section{Molecular chaperones}

A first line of defence are the molecular chaperones (Akerfelt et al., 2010; Buchberger et al., 2010; Hartl et al., 2011). The term 'molecular chaperone' was coined in 1978 in the biological context by Ron Laskey to describe nucleoplasmin which binds histones due to its negative charge (Laskey et al., 1978). The term was extended to proteins that enable the correct folding and assembly of other proteins in 1987 (Ellis, 1987). Similar proteins also augment folding and assembly in prokaryotes and eukaryotes (Hemmingsen et al., 1988; Ostermann et al., 1989). A protein can be defined as a molecular chaperone, if it can interact with non-native proteins, stabilises them or helps them to reach their native conformation, without being present in their final native structure (Hartl and Hayer-Hartl, 2009). Molecular chaperones as proteins are to be distinguished from chemical chaperones, naturally occurring or synthetic small non-proteinogenic molecules, which can also facilitate folding of proteins as well. Chaperones do not contain specific steric information for their respective proteins to fold; however, they prevent unproductive interactions and allow the protein to fold with a higher efficiency into its native structure. They are therefore to be distinguished from folding enzymes, e.g. the peptidyl-prolyl-cis-trans isomerases or protein disulphide isomerases, catalysing covalent bonds (Lang and Schmid, 1988).

It has been demonstrated that Hsp70 chaperones can bind the hydrophobic stretches of many unfolded proteins, whereas the native proteins were not bound. The substrates consisted of a core of amino acids enriched with hydrophobic residues, flanked on both sides by a region with positively charged residues (Rudiger et al., 1997). As mentioned, high temperatures or other environmental changes can force proteins to misfold. However, cells are able to induce a heat shock response (HSR), upregulating protective proteins, especially heat shock proteins. Often, but not always, these heat shock proteins are molecular chaperones and vice versa. Molecular chaperones help proteins to fold, prevent misfolding and aggregation, direct damaged and misfolded proteins to 
the degradation machineries, which are described below, and can sometimes solubilise denatured, misfolded and aggregated proteins. The potential for the induction of the HSR is decreasing with ageing, thus supporting the hypothesis that many proteinopathies manifest with increased age (Hinault et al., 2006; Spurrier et al., 2018). Molecular chaperones do not only occur in the cytoplasm, they are also present and acting in other compartments in the cell, including the nucleus, the ER and mitochondria (Daugaard et al., 2007; Ryan and Hoogenraad, 2007; Tabas and Ron, 2011). Molecular chaperones also play a role in folding and refolding of proteins accessing different cellular compartments, assembly of oligomeric complexes and in shuttling and binding of other proteins and hormones to their receptors (Cheng et al., 1989; Ostermann et al., 1989; Vembar and Brodsky, 2008).

In summary, molecular chaperones are the most important cellular proteins acting against protein misfolding and aggregation. They are embedded in a highly organised network with partly pleiotropic activities to ensure an almost complete coverage of the proteome.

\section{The ubiquitin proteasome system}

There is a close connection between the network of molecular chaperones and the ubiquitin proteasome system (UPS), a central system in eukaryotic cells which degrades proteins and cleaves them into oligomeric peptides. The UPS represents another central line of defence against protein misfolding and aggregation, as these aberrantly folded proteins can be recognised and shuttled to the UPS (Ross and Pickart, 2004). Protein degradation has some important functions in protein quality control. Firstly, proteins of mutated genes, misfolded for instance via aberrant post translational modifications or during heat stress, are rapidly removed. It might be that this second line of defence after the molecular chaperones is necessary, because their capacity is reached and/ or they cannot be enriched fast enough during an HSR. Furthermore, the controlled balance of synthesis and degradation of proteins which are in their native state enables rapid changes in protein levels, for instance, in response to environmental changes and amino acid supply. The third important function of proteasomal degradation is the production of oligomeric peptides which are presented in nearly all nucleated human cells at their surface on the major histocompatibility complex I (MHC I). Interestingly, defective ribosome products (DRiPs), which include incomplete nascent chain products due to premature translation termination or failure to fold properly or to assemble into their multi-subunit protein complexes, are rapidly degraded and may change the pattern of MHC I presentation (Bourdetsky et al., 2014). Components of the UPS are very often detected in aggregates and inclusion bodies, as well as ubiquitination of the aggregating proteins (Sherman and Goldberg, 2001). The signal which targets most proteins for degradation by the proteasome consists of a polyubiquitin chain, a posttranslational modification itself. As the name implies, ubiquitin is a ubiquitously occurring protein in eukaryotic cells, very conserved and only $8.5 \mathrm{kDa}$ in size (VijayKumar et al., 1987). It is ligated to specific lysine residues on target proteins and can be bound in different ways, including monoubiquitin and polyubiquitin in its various forms such as mixed and branched ubiquitin chains (Komander and Rape, 2012).

The highly regulated process of ubiquitination usually encompasses three steps with three types of involved enzymes: activation of ubiquitin with ATP by the ubiquitin-activating enzymes E1, conjugating to the ubiquitin conjugating enzymes E2 and finally transferring on to the substrate proteins via the E3 ligases (Pickart, 2001; Vilchez et al., 2014). Ubiquitin is covalently attached to substrate proteins through K48 residues, but linkage can also occur on cysteine or methionine residues. There are more than 600 putative E3 ligases detected in humans so far, adding to the complexity of the UPS and ensuring the coverage of the human proteome (Li et al., 2008). As mentioned already, there are different adapter proteins involved in the recognition of misfolded proteins, and the E3 ligase carboxyl terminus of Hsc70 interacting protein (CHIP) plays a very central role. It has been shown that CHIP ubiquitinates misfolded Hsp70 and Hsp90 client proteins and targets them for degradation as well as facilitates aggresome formation (Ballinger et al., 1999; Connell et al., 2001). Therefore, it can be seen as a link between the UPS and the system of molecular chaperones (Zhang and Qian, 2011). The polyubiquitinated proteins are then recognised by the proteasome and degraded. The barrel shaped complex of the $20 \mathrm{~S}$ proteasome (S for Svedberg units) binds to 19S regulatory caps and together they form the 26S holo-proteasome. The 19S caps, themselves consisting of several subunits, can recognise ubiquitinated proteins, unfold them and thread them into the $20 \mathrm{~S}$ core, where they are cleaved into oligomers (Ciehanover et al., 1978). Ubiquitin is recycled from the to-be-degraded proteins by deubiquinating enzymes (DUBs) in order to re-fill the pool of ubiquitin in cells again without actually synthesising it and can be regulated by PTMs (Kessler and Edelmann, 2011). Proteasomes reside both in the cytoplasm and in the 
nucleus, and proteins from the endoplasmic reticulum (ER) which are targeted for degradation are retro-translocated towards the cytosolic compartment, where they are degraded. This pathway plays an important role in removing and destroying misfolded proteins in the ER. It is assumed that one third of all proteins make their way to their final destination via the ER and Golgi apparatus, so there needs to be a system in place which can recognise misfolded proteins and refold or degrade them. The response to a heavy load of protein misfolding in the ER is named the unfolded protein response (UPR). Similar to the processes in the cytoplasm, ER resident molecular chaperones are upregulated, and misfolded proteins are targeted for ER-associated degradation (ERAD) (Buchberger et al., 2010; Smith et al., 2011).

\section{Autophagy}

Despite the mentioned cellular systems in place to remove misfolded proteins and maintain proteostasis, it may be that misfolded species may still begin to aggregate and cannot be removed by chaperones or the UPS. In this case, a third and equally important process, autophagy, can take over. Autophagy or autophagocytosis means 'selfeating' and describes a process in which cells degrade their own components or even organelles in membrane coated vesicles (Tsukada and Ohsumi, 1993; Klionsky, 2008; Nikoletopoulou et al., 2015).

There are at least three different types of autophagy known, macroautophagy, microautophagy and chaperone-mediated autophagy (CMA) (Cuervo, 2004; Mizushima and Klionsky, 2007). Microautophagy represents the basal lysosomal degradation, constitutively degrading substrates by direct engulfment of lysosomal membranes (Mortimore et al., 1988). In contrast, macroautophagy and CMA can be modulated by exogenous influences, including heat stress and accumulation of misfolded proteins. Macroautophagy is not only the main autophagic process to degrade protein aggregates, but is also active in destroying damaged cell organelles such as mitochondria ('mitophagy') or unused proteins (Levine et al., 2011). Cytosolic components or organelles are sequestered by double membrane vesicles, the autophagosomes during macroautophagy (Mizushima et al., 2001). These vesicles are marked for fusion with lysosomes, which provide the autophagosomes their hydrolases to degrade the engulfed proteins (Homma et al., 2011). Macroautophagy is a highly regulated process (Behrends et al., 2010) and can be manipulated via the mTOR pathway (Saxton and Sabatini, 2017). mTOR stands for 'mammalian target of rapamycin' and indicates already the route of possible manipulation. It is a sensor for nutrients and cellular energy and can repress macroautophagy when the organism is well supplied with nutrients (Meijer and Codogno, 2004). In contrast, CMA is a more selective autophagocytic process and can selectively degrade soluble cytosolic proteins (Dice, 2007). Proteins to be degraded via CMA can be directly imported into the lysosomal lumen. Chaperones such as the hsc70 complex can recognise a specific pentapeptide motif, often KFERQ, of the substrate protein and a complex consisting a CMA/substrate/chaperone complex is formed. The protein is routed for degradation traffic to the lysosomal membrane and is translocated with augmentation by LAMP2A into the lysosomal lumen (Yamamoto and Yue, 2014).

In summary, cells have developed very sophisticated defence mechanisms against protein misfolding and aggregation. Molecular chaperones recognise them in a first attempt to remove these species and to refold them. If this is not entirely possible, the proteins are degraded via the UPS. If there is a barrier as well or if the UPS is impaired or the UPS capacity insufficient, the aggregated misfolded proteins can be removed via autophagy. If there is excessive material accumulated in the cell, the aggregates are translocated to specific sites and stored in a 'heap', where the harm to the cell is minimised. The misfolded proteins are often targeted to the centrosome or near the centrioles in mammalian cells. Specific machineries, including microtubules and histone deacetylase 6 (Kawaguchi et al., 2003; New et al., 2012), can shuttle the misfolded proteins in a retrograde transport to this central location. Being in an amorphic shape, these central locations with the aggregated material are often referred to as 'aggresomes' (Johnston et al., 1998). Lewy bodies, which are a pathological hallmark in Parkinson's disease (PD), resemble these structures and contain aggresome-specific marker proteins, e.g. tubulin and pericentrin, but also ubiquitin and other components of the UPS and autophagy (Olanow et al., 2004). Lewy bodies and aggresomes in general could therefore represent the endpoint of the misfolding and aggregation. One hypothesis suggests that the formation of the aggresomes reduce the toxic effect of the misfolded species (Arrasate et al., 2004). On the other hand, it is known that essential proteins can be sequestered in the aggregates and they could in this way contribute to the observed cytotoxicity (Olzscha et al., 2011), besides the physical barriers which the cell is facing. If cells are irreparably damaged and essential cellular functions are collapsing due to overwhelming protein misfolding, apoptosis is initiated to protect surrounding cells and tissue (Hickey and Chesselet, 2003). 


\section{Posttranslational modifications}

As the name suggests, PTMs are alterations of proteins occurring after their synthesis on ribosomes. However, it has been demonstrated that proteins can also be cotranslationally modified; examples are $N$-acetylation of $\mathrm{N}$-termini after cleavage of the first amino acid M (Utsumi et al., 2001). Protein folding occurs cotranslationally without PTMs in place, very often proteins fold and then have to be modified in order to reach their final structure and become biologically active. Therefore, PTMs can be crucial for protein folding and activation and proteins can be subject to a tremendous range of posttranslational modifications. The plethora of PTMs can be categorised into structural changes of the backbone protein including proteolysis and proteolytic cleavage of substrates, racemisation and protein splicing (see Figure 3). Many PTMs are irreversible, e.g. the cleavage of proinsulin results in the mature insulin. Chemical modification of proteins can also lead to irreversible PTMs; an example would be the conversion of arginine to citrulline residues in proteins (Smith and Denu, 2009). On the contrary, there are the reversible PTMs. In these cases, various molecules are covalently bound to proteins and can be removed. They can be further divided into inorganic groups such as phosphate, hydroxyl or sulfate groups, and in organic groups, such as methyl, acetyl, or glycosyl groups. Even more complex peptides or proteins can be reversibly added to other proteins, including ubiquitin or small ubiquitin-related modifiers (SUMO). In most cases, the so-called 'writers' add the PTM to the substrate protein, 'erasers' can remove them and 'readers' can recognise the PTM and exert a physiological response (Figure 4, Lahortiga and Cox, 2018). It has become clear over the recent years that PTMs of an individual protein are often functionally connected to other PTMs present on this protein and depend upon each other (Duan and Walther, 2015).

Arguably, protein folding can be seen as a steric posttranslational modification that forces proteins to fold in another structure than the native structure and changing its biological function. Under a well-balanced proteostasis this may not often be the case; however, when it comes to protein misfolding, this concept can be expanded. Extreme examples would be prion proteins

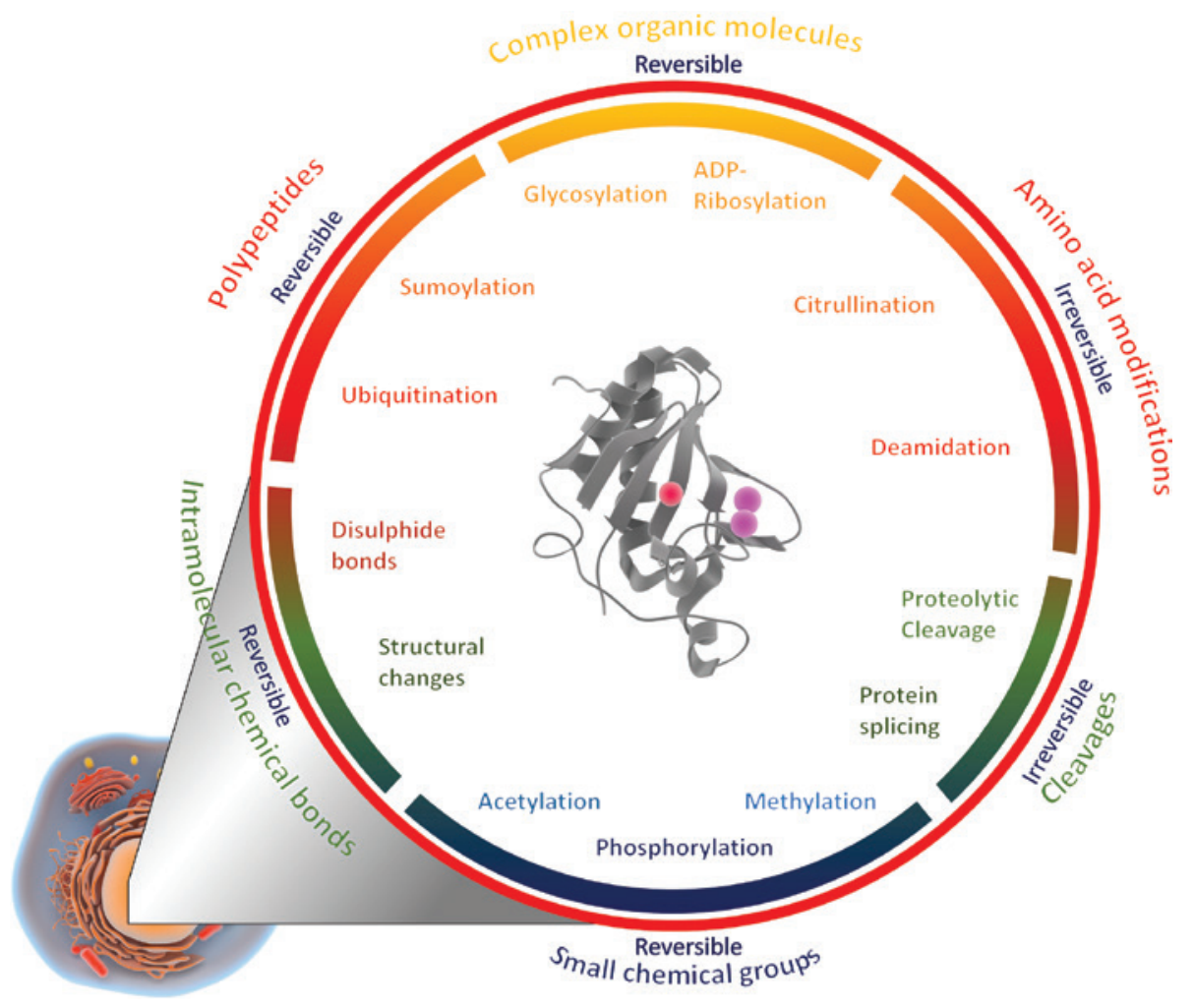

Figure 3: PTMs in mammalian cells classified according to structural and biochemical properties. Different PTMs are grouped according to their chemical and structural properties. At least one member of each group is described in more detail with examples of the underlying proteinopathies, e.g. phosphorylation, ubiquitination, acetylation, glycosylation, citrullination, proteolytic cleavage and structural changes. It is indicated under each group, whether the PTMs are reversible or irreversible. 


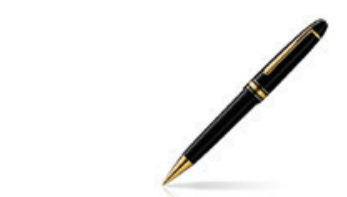

Writers
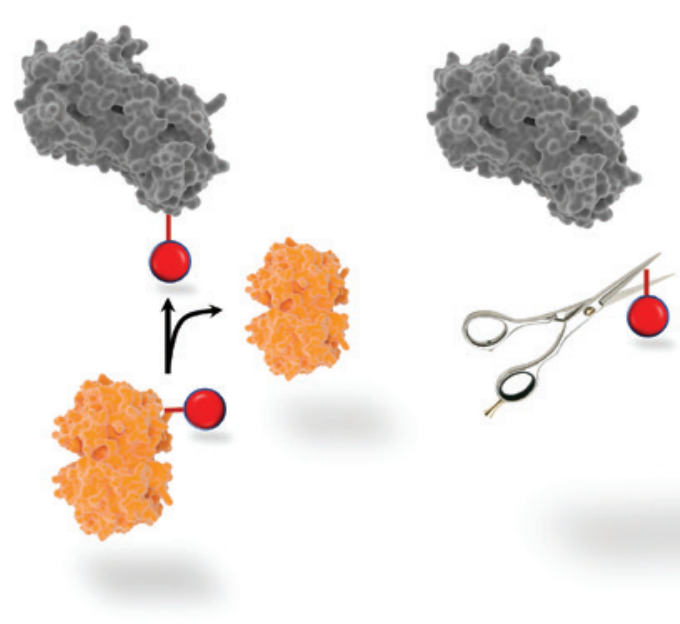

Figure 4: Writers, erasers and readers of PTMs.

A common theme throughout PTMs is the addition of the modifications by 'writers', shown in yellow; the removal of the modifications by 'erasers', if the process is reversible, indicated by a scissor; and the reading of the modification by recognising proteins, the 'readers', shown in green. The protein with the PTM is shown in grey and a PTM itself is depicted as a red sphere. Table 1 provides examples of writers, erasers and readers for specific PTMs and which amino acid residues can be affected.

(Aguzzi et al., 2008). Prions are proteins which can occur in cells both in physiologic or 'normal' structures, and in pathogenic or 'toxic' conformations. The word 'prion' is a portmanteau of the words proteinaceous and infectious (Prusiner, 1982). Misfolded prion proteins in

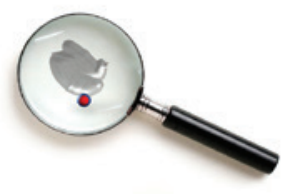

\section{Readers}

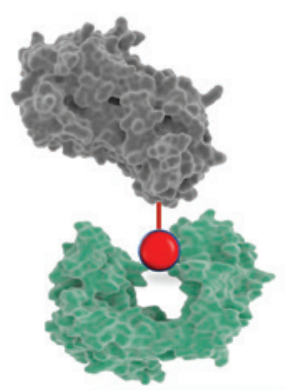

Table 1: Major writers, erasers and readers of posttranslational modifications associated with proteinopathies.

\begin{tabular}{|c|c|c|c|c|c|c|}
\hline PTMs & Residues & Writers & Erasers & $\begin{array}{l}\text { Reader proteins and } \\
\text { domains }\end{array}$ & Proteinopathy & Protein example \\
\hline \multirow[t]{2}{*}{ Phosphorylation } & Y & Kinases & Phosphatases & SH2, PTB & PD & $\alpha$-Synuclein \\
\hline & $\mathrm{S}, \mathrm{T}$ & Kinases & Phosphatases & $\begin{array}{l}\text { 14-3-3, BRCT, FF, WW, } \\
\text { FHA, WD40x8, MH2, } \\
\text { IRF3 }\end{array}$ & $A D$ & Tau \\
\hline Ubiquitination & $\mathrm{K}$ & Ubiquitin ligases (E3s) & $\begin{array}{l}\text { Deubiquiti-nases } \\
\text { (DUBs) }\end{array}$ & $\begin{array}{l}\text { Ubiquitin binding } \\
\text { domains (UBDs) }\end{array}$ & PD & $\alpha$-Synuclein \\
\hline Acetylation & $\mathrm{K}$ & $\begin{array}{l}\text { Histone } \\
\text { acetyltransferases } \\
\text { (HATs) }\end{array}$ & $\begin{array}{l}\text { Histone } \\
\text { deacetylases } \\
\text { (HDACs) }\end{array}$ & $\begin{array}{l}\text { Bromodomains (BRDs), } \\
\text { tandem-PHDs }\end{array}$ & $A D$ & Tau \\
\hline Methylation & $\mathrm{K}, \mathrm{R}$ & Methyltransferases & Demethylases & $\begin{array}{l}\text { PHD, Chromodomains } \\
\text { (CHDs), Tudor, MBT }\end{array}$ & ALS & $\begin{array}{l}\text { Fused in } \\
\text { Sarcoma (FUS) }\end{array}$ \\
\hline$N$-Glycosylation & $\mathrm{N}$ & $\begin{array}{l}\text { Oligosaccharyl- } \\
\text { transferases }\end{array}$ & PNGases & $\begin{array}{l}\text { Various, Fc and other } \\
\text { immune receptors }\end{array}$ & CJD & PrPc, PrPsc \\
\hline Citrullination & $\mathrm{R}$ & $\begin{array}{l}\text { Peptidyl arginine } \\
\text { deiminases (PADs) }\end{array}$ & $\mathrm{N} / \mathrm{A}$ & $\mathrm{N} / \mathrm{A}$ & RA & Fibrinogen \\
\hline
\end{tabular}

ALS, amyotrophic lateral sclerosis (Lou Gehrig's disease); AD, Alzheimer's disease; CJD, Creutzfeldt Jakob disease; PD, Parkinson's disease; RA, rheumatoid arthritis. 


\section{Implication of PTMs on protein folding and proteinopathies}

Posttranslational modifications can alter the folding and structure of proteins and thus modify their biochemical activity. It is therefore possible that posttranslational modifications can lead to dysfunction of proteins and contribute to unfolding or misfolding. A prominent example is the protein Tau in Alzheimer's disease (AD). It is well established that this protein becomes hyperphosphorylated with progressing disease and forms characteristic intracellular neurofibrillary tangles (Wang et al., 2015). On the other hand, protein misfolding itself can lead to altered posttranslational modification, especially when crucial enzymes are involved. An example of this scenario is the enzyme superoxide dismutase 1 (SOD1). This enzyme catalyses the dismutation of the superoxide $\left(\mathrm{O}_{2}^{-}\right)$radical into oxygen $\left(\mathrm{O}_{2}\right)$ or hydrogen peroxide $\left(\mathrm{H}_{2} \mathrm{O}_{2}\right)$. If the enzyme is lacking due to a mutation and aggregating (loss of function) as in amyotrophic lateral sclerosis (ALS), there can be an accumulation of reactive oxygen species (ROS), leading to uncontrolled formation of PTMs and cell death (Deng et al., 1993). Whether the aggregation of SOD itself and the concomitant toxic species or the ROS are causal in the pathophysiology of the disease needs to be confirmed. Protein oxidation has other profound effects on protein folding and misfolding. For instance, methionine oxidation has been detected in misfolded $\operatorname{PrP}^{\mathrm{Sc}}$ to destabilise the native $\operatorname{PrP}^{\mathrm{c}}$ fold as an early event in the conversion pathway (Elmallah et al., 2013). Similarly, tyrosine residues of $\alpha$-synuclein are required for aggregation upon oxidative stress (Olteanu and Pielak, 2004).

Aberrant PTMs of a protein causing protein misfolding can directly lead to its dysfunction, as seen in Tau. However, indirect effects on protein quality control systems in cells can also lead to protein misfolding, aggregation and proteinopathies. As described above, protein aggregation does not necessarily mean that amyloid fibrils are present. However, there are examples where PTMs can affect the formation of amyloid species in cells. Examples and classifications of these different scenarios are provided in the following sections and examples of writers, erasers, readers and associated proteinopathies are provided in Table 1.

\section{Phosphorylation}

A well-known example in which a PTM modifies a protein to adopt an unfolded state with subsequent aggregation, is the already mentioned phosphorylation of Tau in AD. These heat-stable proteins stabilise microtubules (Weingarten et al., 1975), but it has also become apparent that Tau proteins are intrinsically disordered (Zhu et al., 2015). Tau proteins form intracellular insoluble amyloids, which are referred to as neurofibrillary tangles, demarcating them from $A \beta$ aggregates in $A D$. One hypothesis suggests that Tau aggregation is a consequence of $A \beta$ aggregation and that hyperphosphorylation of Tau often precedes the formation of neurofibrillary tangles. The six Tau isoforms detected in humans so far can bind as positively charged proteins to the negatively charged microtubules. There are 79 potential phosphorylation binding sites on the longest Tau isoform, and on average 30 phosphoryl residues are present in the disease-unaffected Tau in human brains (Billingsley and Kincaid, 1997). Hyperphosphorylated Tau can aggregate in proteinopathies, commonly known as tauopathies, with $\mathrm{AD}$ as the most prominent one.

Given that many residues have to be phosphorylated, one would assume that hyperphosphorylation of Tau changes the charge of the protein tremendously, falling apart from the negatively charged microtubules. However, as Tau contains IDRs, it turned out to be very challenging to analyse the structural changes. It also remains unclear whether the observed changes are cause or consequence of Tau aggregation, a physiological response to preceding $A \beta$ aggregation and/or part of a protective quality control mechanism (Engel et al., 2006; Mondragon-Rodriguez et al., 2014). Authors of a study carried out in 2015 using time-resolved electrospray ionization mass spectrometry (TRESI-MS) and hydrogen/ deuterium exchange (HDX) to shed light on these problems came to the conclusion that the structural changes observed in Tau correlate with increasing amyloidogenic propensity upon hyperphosphorylation by glycogen synthase kinase 3 (GSK-3ß) and are therefore causative events in Tau amyloidogenesis (Zhu et al., 2015). The removal of cells with hyperphosphorylated Tau protein in a Tau-dependent neurodegenerative disease MAPT${ }^{P 301 S}$ PS19 mouse model prevented degeneration of cortical and hippocampal neurons, thus preserving cognitive function (Bussian et al., 2018).

Interestingly, the peptide $A \beta$, if equally involved in $\mathrm{AD}$, may precede aggregation of Tau and can be modified by phosphorylation during apoptosis (Sodhi et al., 2008). It has been demonstrated that phosphorylation on T668 (APP 695) increases apoptosis. In accordance with these results, specific extracellular signal regulated kinase (ERK) inhibition upon induction of apoptosis resulted in downregulation of amyloid precursor protein (APP) phosphorylation at T668 and decreased $\mathrm{A} \beta$ secretion response. 


\section{Ubiquitination}

Ubiquitination plays an important role in protein quality control as part of the UPS and autophagy, as explained in the sections above. It has becoming increasingly apparent that ubiquitin is directly or indirectly involved in most of the degradation processes occurring in proteinopathies, either via the UPS or autophagy. A prominent example in which ubiquitin accompanies protein misfolding of a defined protein during progression of a proteinopathy, is $\alpha$-synuclein found in Lewy bodies in PD, in dementia with Lewy bodies or in multiple system atrophy, the socalled synucleinopathies (Spillantini et al., 1997). The name ' $\alpha$-synuclein' is again a portmanteau, in this case of the words 'synapsis' and 'nuclein', indicating that it is a nuclear protein in synaptic cells (Maroteaux et al., 1988). Depending on the isoforms generated by alternative splicing, $\alpha$-synuclein is a small $11-14 \mathrm{kDa}$ protein with uncertain function; however, some reports suggests that it is involved in stabilising the intracellular cytoskeleton, vesicle trafficking and fusion (Cooper et al., 2006; Burre et al., 2010). Lewy bodies are intracytoplasmic inclusions with a core of granular and filamentous material surrounded by radially filaments (Forno, 1996). Evidence for the ubiquitination of $\alpha$-synuclein was given in a study about sporadic Lewy body diseases. The 22-24 kDa species were not only found to be phosphorylated, but also ubiquitinated with one, two and/or three ubiquitins, rather than polyubiquitin (Tofaris et al., 2003). In line with this observation, the authors did not provide evidence for a generalised impairment of the UPS in brain regions with Lewy body pathology, arguing for the hypothesis that autophagy is a key event in the processing of misfolded material in PD (Pan et al., 2008). On the other hand, there are many reports about the contribution of the UPS in $\alpha$-synuclein degradation and how UPS impairment may increase the detrimental aggregation of the protein (McNaught et al., 2002). In the end, these contrary observations may be site and time specific, and dependent on how far the disease of the patient has progressed. It could be hypothesised (as stated in the section 'autophagy') that autophagy is upregulated after the capacity of the UPS has been reached and takes on the often impossible task to degrade the large aggregates in aggresomes. In both scenarios, ubiquitin would be attached to target the substrates for degradation. As ubiquitin is very abundant in Lewy bodies, it was used for some years to indirectly determine the presence of Lewy bodies in synucleinopathies before better antibodies against $\alpha$-synuclein were developed (Beach et al., 2009).

A recent study linked the effects of several PTMs on the fate of Tau. A novel HDAC inhibitor, MPTOG211, was tested and resulting HDAC6 inhibition resulted in an increase in acetylated Hsp90, leading to decreased Hsp90 and ultimately causing ubiquitination of phosphorylated Tau. These effects correlated with ameliorated learning and memory impairment (Fan et al., 2018).

\section{Acetylation}

Acetylation is one of the most abundant modifications on proteins; in fact, there are more than 6000 proteins known in humans which can be acetylated (Choudhary et al., 2009; Xu et al., 2017). The percentage of acetylated proteins is even higher in bacteria; for instance, more than about $90 \%$ of the enzymes of central metabolism in S. enterica were found to be acetylated (Wang et al., 2010). Protein acetylation is one example where the modification can be added cotranslationally and posttranslationally. Protein acetylation can be divided into $N$-terminal acetylation and lysine acetylation. $N$-terminal acetyl residues are usually already cotranslationally added and up to $85 \%$ of the eukaryotic proteome is $N$-terminally acetylated, illustrating the importance of this protein modification (Van Damme et al., 2011). Lysine acetylation can be executed cotranslationally and posttranslationally by histone acetyltransferases. The names 'histone acetyltransferases' and 'histone deacetylases' for the erasers of acetylation have historical reasons and it is now known that both histones and various other proteins can be acetylated and deacetylated (New et al., 2012; Olzscha et al., 2016). Type A histone acetyltransferases are located in the nucleus, whereas type Bs resides in the cytoplasm, implying that a substantial amount of acetylation is posttranslationally added. The number and localisation of the histone deacetylases is even more complex. Including the sirtuins, there are 18 histone deacetylases in the human proteome with different specificities and localisations in the nucleus and cytoplasm (Olzscha et al., 2015). Lysine is a positively charged amino acid and acetylation neutralises this charge. This might be one reason why lysine acetylation of histones relaxes chromatin, contributes to epigenetic changes and regulates transcription, as the DNA becomes less compact.

Besides the epigenetic aspects of lysine acetylation, the changes in charge can also affect the structure of proteins and therefore the folding. Some examples how protein acetylation can influence protein folding, misfolding and the surveilling protein quality control systems are given below.

Several studies have shown the connection between the UPS and autophagy. As mentioned in the section 
above, ubiquitin plays an important role in the degradation of proteins via the proteasome and autophagy. However, it has been demonstrated how protein acetylation links the two eminent protein quality control systems UPS and autophagy. New et al. demonstrated in 2013 that the histone deacetylase 6 (HDAC6), an HDAC resident in the cytosol, can downregulate HR23B. HR23B belongs to the group of proteasomal shuttling factors that are able to bind ubiquitinated species via its ubiquitin-binding domain (UbA) and facilitate their delivery to the proteasome (Hiyama et al., 1999). HR23B is also a sensitivity determinant to HDAC inhibitors, for instance, to the pan-HDAC inhibitor vorinostat. Co-IP experiments with different deletion mutants of both HDAC6 and HR23B showed that they can interact via the UbA and HDAC6 BUZ domain, which can bind ubiquitinated species as well and is involved in targeting them along microtubules towards the location of aggresomes as mentioned above. As a result, HR23B and HDAC6 link the formation of aggresomes and autophagy with the UPS (New et al., 2013) (Figure 5).

HDAC inhibitors can be causative in forcing cells expressing high levels of HR23B into apoptosis, whereas in cells with lower expression, HDAC inhibitor treatment is frequently correlated with autophagy. The responsible mechanism involves the interaction of HDAC6 with HR23B, which downregulates HR23B and therefore decreases the amount of ubiquitinated substrates targeted to the proteasome, eventually desensitising cells to apoptosis. Importantly, the ability of HDAC6 to downregulate HR23B functions independently of its deacetylase activity. An analysis of the HDAC6 interactome identified HSP90 as a key effector of HDAC6 on HR23B levels. These results define a regulatory mechanism that involves the interplay between HR23B and HDAC6 that influences the biological outcome of HDAC inhibitor treatment and the two major degradation systems in cells (Figure 6).

An example where acetylation plays a crucial role in protein folding and neurodegenerative disease is again the above-mentioned protein Tau. The most commonly described change in its phosphorylation state is from 'euphosphorylation' to 'hyperphosphorylation'. According to the amyloid-cascade hypothesis as described above in the section 'phosphorylation', it is assumed that extracellular aggregation of $\mathrm{A} \beta$ leads to posttranslational and

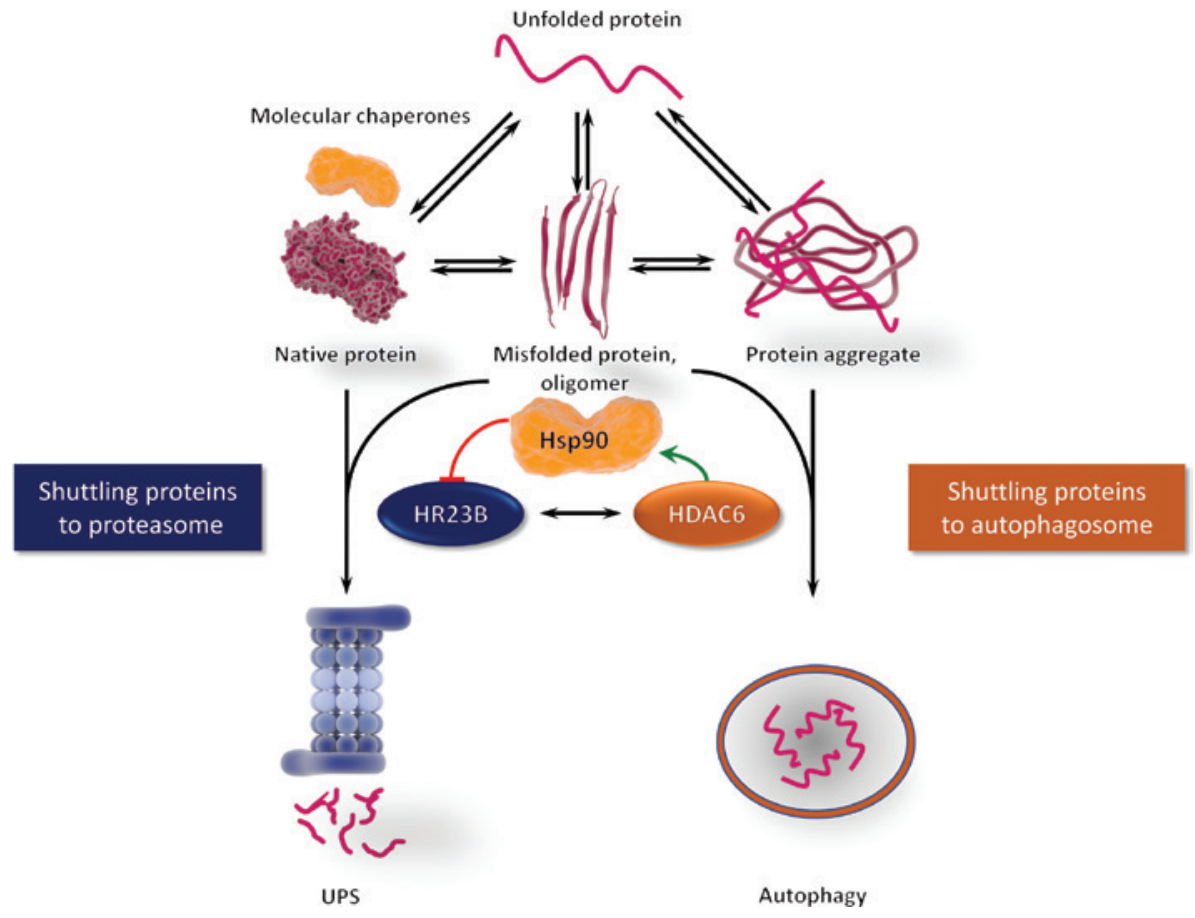

Figure 5: Interplay between three major protein quality control systems.

Molecular chaperones, the UPS and the components of autophagy do not act independently of each other and usually react to protein misfolding in a concerted action. Molecular chaperones (yellow) can recognise unfolded proteins and aggregates (dark red) and refold them or prevent misfolding. HR23B (dark blue) is a proteasome shuttling factor which can facilitate protein degradation of ubiquitinated proteins. HDAC6 (orange) plays a similar role for the formation of aggresomes and in autophagy. HDAC6 can bind HR23B via its BUZ domain and can regulate the molecular chaperone Hsp90 via acetylation. Hsp90 can interfere with HR23B mediated protein degradation and initiate a feedback loop (New et al., 2013). 


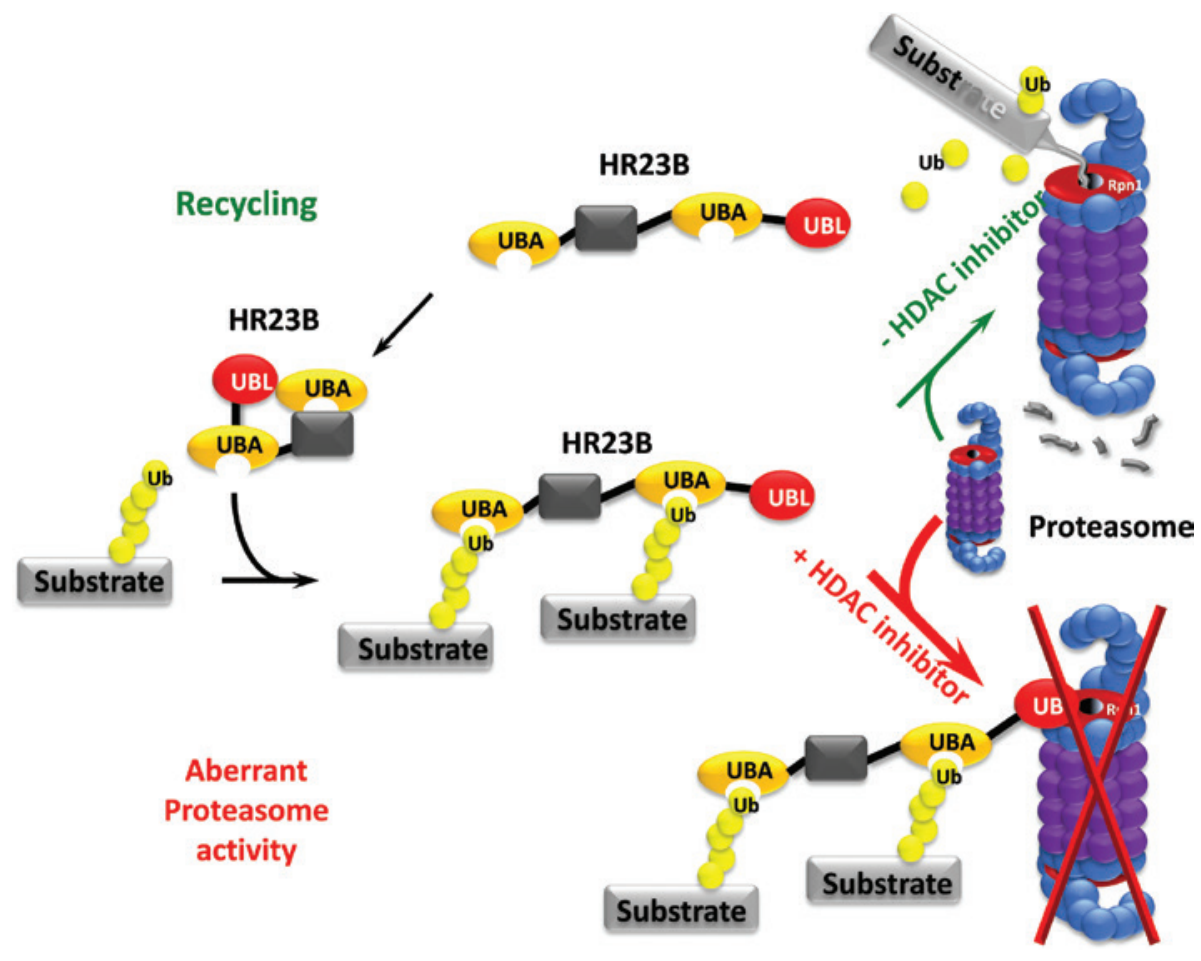

Figure 6: Impact of acetylation on the UPS.

Protein hyperacetylation can lead to impairment of the ubiquitin proteasome system, and HR23B as a proteasome shuttling factor is a sensitivity determinant for HDAC inhibition. Substrate proteins (grey) can be ubiquitinated (yellow) and HR23B can bind ubiquitinated substrate proteins via its UBA domain. HR23B then shuttles the substrate proteins towards the proteasome, where they are degraded. HR23B, which is non-covalently bound, is then recycled as well as ubiquitin. Upon HDAC inhibition, the equilibrium of HR23B acetylation is shifted towards the acetylated form and protein shuttling is impaired. This can be of significance, if misfolded proteins are targeted for degradation.

conformational changes of tau. However, acetylation of Tau at K174 changes tau homeostasis and toxicity, as well as the pathological state in soluble Tau (Min et al., 2015). It is believed that p300 plays a pivotal role in acetylating the K174 Tau residue.

Another recent study using novel semi-synthetic strategies for a site-specific introduction of PTMs demonstrated that acetylation at K280 significantly enhances the aggregation rate of Tau and impairs microtubule assembly. In addition, the acetylated Tau formed mainly globular oligomers and short fibrils in line with enhanced aggregation propensity and pathogenicity in animal models of $\mathrm{AD}$, leading to the assumption that this modified Tau might enhance the seeding capacity or formation of toxic Tau species (Haj-Yahya and Lashuel, 2018).

The important role of the histone acetyltransferase p300 was underlined by a more recent global study investigating the effect of protein hyperacetylation on misfolding and aggregation (Olzscha et al., 2017). Interestingly, p300 is not only a transcription activator and histone acetyltransferase, it also contains a bromodomain. Bromodomain containing proteins are the readers of lysine acetylation, and p300 and the similar CREB binding protein (CBP) can bind acetylated proteins, facilitating further acetylation. Hyperacetylation of proteins induced by pan-HDAC inhibitors in clinically relevant concentrations led to the formation of aggregates with amyloid-containing structures. p300/ CBP were part of these structures and found in the aggregates. Moreover, indispensable protein quality control systems including the UPS and autophagy were impaired. Aggregates could be partly resolved when p300/CBP-specific newly developed bromodomain inhibitors were applied and proteostasis restored. In addition, as glutamine residues resemble structurally to a certain extent acetylated lysine residues (Fujimoto et al., 2012), the inhibitors were tested on pathologically elongated huntingtin. Huntington's disease (HD) is one of the polyglutamine disorders whereby in patients the polyglutamine stretch exceeds a normal range of approximately 36 glutamine residues (Walker, 2007). Pathologically elongated huntingtin was susceptible to the p300/CBP-specific bromodomain inhibitors and the aggregates were at least partly resolved. 
HDAC inhibitors are routinely applied in haematological malignancies and the before-mentioned results implicate a contribution of protein misfolding in HDAC inhibitor-induced cell death (Olzscha et al., 2015).

\section{Glycosylation}

As approximately one third of all eukaryotic proteins are imported into the lumen of the ER and towards the Golgi apparatus, co- or posttranslational modifications play an important role in altering the structure and functions of these proteins. Indeed, $\mathrm{N}$-glycosylation can stabilise the native state and lower the activation barrier for folding of substrate proteins. In particular, the first GlcNAc residue has the strongest influence on the stability and the kinetics of protein folding, e.g. $65 \%$ and $100 \%$ of the total $N$-glycan's contribution to hCD2d folding (Hanson et al., 2009).

A paradigm for protein glycosylation and its impact on protein folding and misfolding is given by prion proteins in prion diseases. The alternative term 'transmissible spongiform encephalopathies' (TSE) refers to the pathological picture of the prion diseases, which can occur in humans and many other species. The cellular 'good' version of the prion protein $\operatorname{PrP}^{\mathrm{C}}$ can be converted to the pathologic 'bad' form $\mathrm{PrP}^{\mathrm{sc}}$, which is the most abundant component in the aggregates and evidently the infectious agent, although their primary sequences can be the same. Interestingly, there are reports that the concept of prions in the physiologically normal form being converted into an abnormal form of $\mathrm{PrP}^{\mathrm{SC}}$, can be expanded to other proteinopathies, including AD, PD and HD (Pecho-Vrieseling et al., 2014; Wu et al., 2016). Human PrP has a glycosylphosphatidylinositol (GPI) anchor and it has been shown in a recent report that $N$-linked glycosylation of PrP inhibits its aggregation and decreases cytotoxicity (Yi et al., 2018). The result could lead to the conclusion that aggregation in cells is either diminished due to PrP's glycosylation and tethering to the membrane or that glycosylation changes the folding of PrP, whereby these hypotheses would not exclude each other.

It was reported in a study from 2015 that glycosylation might also impact on the processing of the amyloid precursor protein (APP) (Chun et al., 2015). APP, playing a pivotal role in $\mathrm{AD}$, is transported to the plasma membrane, where it is sequentially cleaved by $\alpha$-secretase and $\gamma$-secretase. Once APP undergoes clathrin-dependent endocytosis, it can be sequentially cleaved by $\beta$-secretase and $\gamma$-secretase at endosomes, producing $A \beta$ (amyloidogenic pathway). It was shown that O-GlcNAcylation of APP increases the non-amyloidogenic pathway and in a follow-up study it was hypothesised that O-GlcNAcylation promotes plasma membrane localization of APP and enhances the nonamyloidogenic processing of APP (Chun et al., 2015).

With a similar synthetic protein chemistry approach as mentioned in the study (Haj-Yahya and Lashuel, 2018) in the section above, the effect of O-GlcNAcylation on $\alpha$-synuclein was analysed. Different O-GlcNAcylated forms of $\alpha$-synuclein were analysed showing that they had site-specific inhibitory effects on the aggregation and cellular toxicity of $\alpha$-synuclein, which could be interesting for potential treatment of PD (Levine et al., 2019).

\section{Citrullination}

Citrullination in proteins means the conversion from an arginine residue to citrulline, which has to be distinguished from the free metabolic citrulline. Citrullination in proteins is a one-way reaction; as far as we know, there is no conversion back to arginine after the release of ammonium. Proteins lose approximately one Dalton in size and a positive charge when ammonium is released. It may well be that the alteration in charge leads to the observed misfolding of various proteins.

Citrullination can be also considered as an ageingrelated PTM, as the citrullination of arginine is irreversible. It was first reported that citrullination can affect the propensity of $A \beta 1-42$ to form amyloid fibrils in 2016. In this study, an R5Cit of A $\beta 1-40$ and A $\beta 1-42$ was introduced and the effect on fibrillization measured. Whereas R5Cit in $\mathrm{A} \beta 1-40$ did not affect the fibrillization rate, conversion of R5 into Cit in A $31-42$ lead to an increased solubility in aqueous solutions and a slower fibril formation compared to unmodified A $\beta 1-42$. Thioflavin $\mathrm{T}$ staining also demonstrated an increased fraction of soluble oligomers during the process of fibrillation (Osaki and Hiramatsu, 2016).

Arginine residues can be both methylated and citrullinated, and they can basically compete against each other (Ghari et al., 2016), similar to ubiquitination and acetylation on lysine residues. However, as mentioned above, citrullination is very likely not reversible, in contrast to $R$ methylation or $\mathrm{K}$ ubiquitination and acetylation. A recent study revealed a more global effect of citrullination on protein aggregation, whereby citrullination may play a protective role in ALS (Tanikawa et al., 2018). It has been demonstrated in this study that proteins with a consensus motif of RG/RGG were preferentially recognised by peptidyl arginine deiminase 4 (PAD4), a nuclear enzyme which executes the conversion of arginine to citrulline residues. The authors also explained that PAD4 competitively 
inhibited methylation of the motif in FET (FUS, EWS and TAF15) proteins as well as in hnRNPA1, which are linked to ALS. The aggregation of these proteins was diminished, when this motif became citrullinated by PAD4. These observations would not support the hypothesis that citrullination would generally facilitate misfolding and aggregation. However, it may be that different changes of proteins, such as mutations and different PTMs could compensate for each other.

It is well established that citrullination plays a crucial role in the pathogenesis of rheumatoid arthritis (RA) (Wegner et al., 2010). Protein citrullination increases with ageing and is therefore not solely a hallmark of RA. However, the detection of auto-antibodies specifically recognising citrullinated proteins can be noted as a pathognomonic sign of RA. For instance, they are not characteristic for osteoarthritis and are already used as a biomarker to detect and predict RA. On average, $80 \%-$ $90 \%$ of RA patients produce anti-citrullinated peptide antibodies (ACPAs), indicating that a structural change of proteins with aberrant citrullination patterns might be recognised (Sakkas et al., 2014). Genetic predispositions such as different HLA-DRs may alter the risk of developing autoantibodies (van der Helm-van Mil et al., 2006). It may be that a certain subset of proteins misfold upon citrullination and induce an immune response, recognised by antibodies which might be also differently glycosylated (Rombouts et al., 2016).

\section{Proteolytic cleavage}

It is somehow astonishing that the various misfolding and aggregating proteins contributing to human proteinopathies are extremely heterogenous in their sequence, even though some of them can adopt the amyloid fold. However, many of the aggregating proteins are very short and it would be even appropriate to term their aggregating parts as polypeptides (Knowles et al., 2014). Many proteins involved in proteinopathies are posttranslationally processed, i.e. cleaved, and misfolded in their shortened version. It has been briefly mentioned above that $A \beta$ is the product of cleavage and depending on the involved secretases, this toxic short peptide with 40-42 amino acid residues emerges from its precursor protein APP (Steiner et al., 2008).

Beyond the APP cleavage and release of $A \beta$, there are other causative proteins in proteinopathies which must be cleaved to exert their function or dysfunction. One example is again the already above-mentioned huntingtin and other polyQ proteins. It has been demonstrated by several groups that huntingtin can be cleaved by caspase- 3 and -6 , leading to an enhanced aggregation propensity by the generated fragments (Graham et al., 2006; Aharony et al., 2015). In addition, caspase inhibitors could reduce the toxicity of pathologically elongated huntingtin and also have a lower ability to form aggregates. Likewise, huntingtin mutants resistant to caspase- 3 and -6 cleavages with an elongated polyQ stretch displayed reduced toxicity in stressed neuronal cells. Thus, caspase inhibition could have a potential therapeutic benefit in HD (Aharony et al., 2015).

Haemodialysis-related amyloidoses (HDRA) are of interest with regard to proteolysis and cleavage. HDRA are examples of iatrogenic diseases occurring during long-term haemodialysis in which $\beta 2$-microglobulin $(\beta 2 \mathrm{~m})$ has been detected as the causative protein producing amyloid fibrils (Gejyo et al., 1985). The disease strikes in patients with dialysis and those undergoing all types of renal replacement therapy. The amyloidoses can be also classified as systemic amyloidoses, although most of the amyloid material aggregates in the joints. Amyloid material biopsied from joints of these patients consists of full-length wild-type $\beta 2$-microglobulin, but also cleaved species and other PTMs have been identified (Linke et al., 1986). Generated cleavages of 7-99 truncated forms of $\beta 2 \mathrm{~m}$ revealed that it has a strong propensity to aggregate, and these species were detected in up to $30 \%$ of biopsies (Bellotti et al., 1998; Relini et al., 2008). The cleavage does not only occur in patients, it is believed to induce the activation of lymphocytes as a response to MHC I binding in general (Nissen et al., 1990).

\section{Conclusion and discussion}

Over the last decade, it has become clear that posttranslational modifications can profoundly alter the structure and folding of proteins, and very often contribute to misfolding with subsequent aggregation. However, a PTM for a given protein is not necessarily the sine qua non for misfolding, as the example of $\mathrm{Htt}$ demonstrates. In this case, aggregation is possible with the full-length huntingtin containing the pathologically elongated polyQ stretch, but can be enhanced upon cleavage by caspases. It may also serve as an example how the aggregation process can be accelerated.

As mentioned, many of the underlying proteins in proteinopathies do not share a common sequence motif or homology. However, many of them are relatively short, sometimes because of proteolytic cleavage, and many of 
them contain one or more IDRs. That leads to the question of whether the already fragile proteins with IDRs are more likely to be destabilised by PTMs and whether PTMs do occur more often in IDRs. These questions may even lead to a new classification of PTM groups, where these modifications are being either associated with structured regions or with IDPs (Xie et al., 2007). It might be that the IDRs are more susceptible to PTMs, for instance in competing with writers, and are consequently in more danger of misfolding.

As described in the section 'protein folding, misfolding and aggregation', evolution seemed to have selected against protein misfolding. But why do organisms then face proteinopathies? Why did proteins such as $A \beta$, Tau or huntingtin escape the selection? Partly, some of these questions may be explained by the ageing-related aspect of the diseases. The age of onset is very often in the $40 \mathrm{~s}$ or beyond, when proteostatic capacities decline. It is therefore unlikely that evolution will eradicate protein misfolding in humans, as they become manifest after the reproduction phase, and the same applies for aberrant PTMs as in Tau.

Another interesting topic are prions. PrPs can be glycosylated and this may also contribute to misfolding and the strain aspect. Some may also argue that the conversion of structure from benign to toxic can be seen as a PTM. This conversion occurs non-enzymatically yet needs templates to be exerted. In line with this view, conventional PTMs such as acetylation or citrullination, which strongly impact on protein structure, can eventually act as 'drivers' for the conversion of proteins with prion-like properties.

It also remains unclear how molecular chaperones generally deal with PTMs, and how aberrant PTMs contribute to protein misfolding in particular. Some aspects of client recognition by molecular chaperones are described in section 'protective mechanisms and protein quality control', and it could be that hydrophobic stretches flanked by positively charged amino acid residues are recognised in a different way or are even not recognised. This could contribute to misfolding, where PTMs are involved.

Many potential treatment options have been put forward to cure proteinopathies. However, and this is especially true for neurodegenerative diseases, there are so far only symptomatic treatments routinely applied, whereas curative or disease-modifying treatments failed. It may be argued that it should not even be distinguished between symptomatic treatments and disease-modifying treatments (Doody, 2008). Again, the ageing aspect has to be taken into account, when proteins begin to misfold. It may already be too late to begin treatment, as shown in hundreds of clinical trials, for instance with antibodies targeting the misfolded proteins, to inhibit their processing or cleavage of the precursors such as gamma secretase inhibitors, to prevent aggregation or reduce inflammation (https://clinicaltrials.gov/). Interestingly, drugs which increase the proteasome workload and those which inhibit the proteasome such as bortezomib can have synergistic effects and are routinely used in treatment of multiple myeloma. Besides genomemodifying treatments where ethical aspects have to be considered and RNA interference (RNAi), an increase of the protein quality control capacity could be another suitable therapeutic approach. The usage of proteolysis targeting chimeras (PROTACs), consisting for instance of cereblon, opens exciting possibilities to interfere with protein quality control machineries (Huang and Dixit, 2016). However, as these systems are interconnected, it is likely that all systems need to be equally targeted. Also, there should be different treatment options for different patients and different mutations, in order to fulfil the 'ultimate aim of personalised medicine, to define the right drug for the right patient at the right time' (Olzscha et al., 2013). It has been demonstrated for molecular chaperones and autophagy that core components can be upregulated, and even for the UPS some individual components can be increased. However, it is yet to be proven whether this can be executed in a tissue-specific, concerted manner.

Acknowledgements: The author acknowledges Emily Hoogkamer for critical reading of the manuscript and support from the federal state of Saxony-Anhalt, MartinLuther-University Halle-Wittenberg, Medical Faculty.

\section{References}

Aguzzi, A., Baumann, F., and Bremer, J. (2008). The prion's elusive reason for being. Annu. Rev. Neurosci. 31, 439-477.

Aharony, I., Ehrnhoefer, D.E., Shruster, A., Qiu, X., Franciosi, S., Hayden, M.R., and Offen, D. (2015). A Huntingtin-based peptide inhibitor of caspase- 6 provides protection from mutant Huntingtin-induced motor and behavioral deficits. Hum. Mol. Genet. 24, 2604-2614.

Akerfelt, M., Morimoto, R.I., and Sistonen, L. (2010). Heat shock factors: integrators of cell stress, development and lifespan. Nat. Rev. Mol. Cell Biol. 11, 545-555.

Anfinsen, C.B., Haber, E., Sela, M., and White Jr, F.H. (1961). The kinetics of formation of native ribonuclease during oxidation of the reduced polypeptide chain. Proc. Natl. Acad. Sci. USA 47, 1309-1314. 
Arndt, V., Dick, N., Tawo, R., Dreiseidler, M., Wenzel, D., Hesse, M., Furst, D.O., Saftig, P., Saint, R., Fleischmann, B.K., et al. (2010). Chaperone-assisted selective autophagy is essential for muscle maintenance. Curr. Biol. 20, 143-148.

Arrasate, M., Mitra, S., Schweitzer, E.S., Segal, M.R., and Finkbeiner, S. (2004). Inclusion body formation reduces levels of mutant huntingtin and the risk of neuronal death. Nature 431, 805-810.

Balch, W.E., Morimoto, R.I., Dillin, A., and Kelly, J.W. (2008). Adapting proteostasis for disease intervention. Science 319, 916-919.

Balchin, D., Hayer-Hartl, M., and Hartl, F.U. (2016). In vivo aspects of protein folding and quality control. Science 353, aac4354.

Ballinger, C.A., Connell, P., Wu, Y., Hu, Z., Thompson, L.J., Yin, L.Y., and Patterson, C. (1999). Identification of CHIP, a novel tetratricopeptide repeat-containing protein that interacts with heat shock proteins and negatively regulates chaperone functions. Mol. Cell Biol. 19, 4535-4545.

Beach, P.S., Bar-on, M., Baldwin, C., Kittredge, D., Trimm, R.F., and Henry, R. (2009). Evaluation of the use of an interactive, online resource for competency-based curriculum development. Acad. Med. 84, 1269-1275.

Behrends, C., Sowa, M.E., Gygi, S.P., and Harper, J.W. (2010). Network organization of the human autophagy system. Nature 466, 68-76.

Bellotti, V., Stoppini, M., Mangione, P., Sunde, M., Robinson, C., Asti, L., Brancaccio, D., and Ferri, G. (1998). Beta2-microglobulin can be refolded into a native state from ex vivo amyloid fibrils. Eur. J. Biochem. 258, 61-67.

Bence, N.F., Sampat, R.M., and Kopito, R.R. (2001). Impairment of the ubiquitin-proteasome system by protein aggregation. Science 292, 1552-1555.

Billingsley, M.L. and Kincaid, R.L. (1997). Regulated phosphorylation and dephosphorylation of tau protein: effects on microtubule interaction, intracellular trafficking and neurodegeneration. Biochem. J. 323, 577-591.

Bourdetsky, D., Schmelzer, C.E., and Admon, A. (2014). The nature and extent of contributions by defective ribosome products to the HLA peptidome. Proc. Natl. Acad Sci. U.S.A. 111, E1591-1599.

Broome, B.M. and Hecht, M.H. (2000). Nature disfavors sequences of alternating polar and non-polar amino acids: implications for amyloidogenesis. J. Mol. Biol. 296, 961-968.

Buchberger, A., Bukau, B., and Sommer, T. (2010). Protein quality control in the cytosol and the endoplasmic reticulum: brothers in arms. Mol. Cell 40, 238-252.

Burre, J., Sharma, M., Tsetsenis, T., Buchman, V., Etherton, M.R., and Sudhof, T.C. (2010). Alpha-synuclein promotes SNARE-complex assembly in vivo and in vitro. Science 329, 1663-1667.

Bussian, T.J., Aziz, A., Meyer, C.F., Swenson, B.L., van Deursen, J.M., and Baker, D.J. (2018). Clearance of senescent glial cells prevents tau-dependent pathology and cognitive decline. Nature $562,578-582$.

Buxbaum, J.N. and Linke, R.P. (2012). A molecular history of the amyloidoses. J. Mol. Biol. 421, 142-159.

Cheng, M.Y., Hartl, F.U., Martin, J., Pollock, R.A., Kalousek, F., Neupert, W., Hallberg, E.M., Hallberg, R.L., and Horwich, A.L. (1989). Mitochondrial heat-shock protein hsp60 is essential for assembly of proteins imported into yeast mitochondria. Nature 337, 620-625.

Chiti, F. and Dobson, C.M. (2006). Protein misfolding, functional amyloid, and human disease. Annu. Rev. Biochem. 75, 333-366.
Chiti, F., Stefani, M., Taddei, N., Ramponi, G., and Dobson, C.M. (2003). Rationalization of the effects of mutations on peptide and protein aggregation rates. Nature 424, 805-808.

Choudhary, C., Kumar, C., Gnad, F., Nielsen, M.L., Rehman, M., Walther, T.C., Olsen, J.V., and Mann, M. (2009). Lysine acetylation targets protein complexes and co-regulates major cellular functions. Science 325, 834-840.

Chun, Y.S., Park, Y., Oh, H.G., Kim, T.W., Yang, H.O., Park, M.K., and Chung, S. (2015). O-GlcNAcylation promotes non-amyloidogenic processing of amyloid-beta protein precursor via inhibition of endocytosis from the plasma membrane. J. Alzheimers Dis. 44, 261-275.

Ciehanover, A., Hod, Y., and Hershko, A. (1978). A heat-stable polypeptide component of an ATP-dependent proteolytic system from reticulocytes. Biochem. Biophys. Res. Commun. 81, 1100-1105.

Ciryam, P., Tartaglia, G.G., Morimoto, R.I., Dobson, C.M., and Vendruscolo, M. (2013). Widespread aggregation and neurodegenerative diseases are associated with supersaturated proteins. Cell Rep. 5, 781-790.

Connell, P., Ballinger, C.A., Jiang, J., Wu, Y., Thompson, L.J., Hohfeld, J., and Patterson, C. (2001). The co-chaperone CHIP regulates protein triage decisions mediated by heat-shock proteins. Nat. Cell Biol. 3, 93-96.

Cooper, A.A., Gitler, A.D., Cashikar, A., Haynes, C.M., Hill, K.J., Bhullar, B., Liu, K., Xu, K., Strathearn, K.E., Liu, F., et al. (2006). Alpha-synuclein blocks ER-Golgi traffic and Rab1 rescues neuron loss in Parkinson's models. Science 313, 324-328.

Cuervo, A.M. (2004). Autophagy: in sickness and in health. Trends Cell Biol. 14, 70-77.

Daugaard, M., Rohde, M., and Jaattela, M. (2007). The heat shock protein 70 family: highly homologous proteins with overlapping and distinct functions. FEBS Lett. 581, 3702-3710.

Deng, H.X., Hentati, A., Tainer, J.A., Iqbal, Z., Cayabyab, A., Hung, W.Y., Getzoff, E.D., Hu, P., Herzfeldt, B., Roos, R.P., et al. (1993). Amyotrophic lateral sclerosis and structural defects in $\mathrm{Cu}, \mathrm{Zn}$ superoxide dismutase. Science 261, 1047-1051.

Deuerling, E. and Bukau, B. (2004). Chaperone-assisted folding of newly synthesized proteins in the cytosol. Crit. Rev. Biochem. Mol. Biol. 39, 261-277.

Dice, J.F. (2007). Chaperone-mediated autophagy. Autophagy 3, 295-299.

Dobson, C.M. and Ellis, R.J. (1998). Protein folding and misfolding inside and outside the cell. EMBO J. 17, 5251-5254.

Doody, R.S. (2008). We should not distinguish between symptomatic and disease-modifying treatments in Alzheimer's disease drug development. Alzheimers Dement. 4, S21-25.

Duan, G. and Walther, D. (2015). The roles of post-translational modifications in the context of protein interaction networks. PLoS Comput. Biol. 11, e1004049.

Eisenberg, D. and Jucker, M. (2012). The amyloid state of proteins in human diseases. Cell 148, 1188-1203.

Ellis, J. (1987). Proteins as molecular chaperones. Nature 328, 378-379.

Elmallah, M.I., Borgmeyer, U., Betzel, C., and Redecke, L. (2013). Impact of methionine oxidation as an initial event on the pathway of human prion protein conversion. Prion 7, 404-411.

Engel, T., Hernandez, F., Avila, J., and Lucas, J.J. (2006). Full reversal of Alzheimer's disease-like phenotype in a mouse model with conditional overexpression of glycogen synthase kinase-3. J. Neurosci. 26, 5083-5090. 
Etchells, S.A. and Hartl, F.U. (2004). The dynamic tunnel. Nat. Struct. Mol. Biol. 11, 391-392.

Fan, S.J., Huang, F.I., Liou, J.P., and Yang, C.R. (2018). The novel histone de acetylase 6 inhibitor, MPTOG211, ameliorates tau phosphorylation and cognitive deficits in an Alzheimer's disease model. Cell Death Dis. 9, 655.

Fitzpatrick, A.W., Debelouchina, G.T., Bayro, M.J., Clare, D.K., Caporini, M.A., Bajaj, V.S., Jaroniec, C.P., Wang, L., Ladizhansky, V., Muller, S.A., et al. (2013). Atomic structure and hierarchical assembly of a cross-beta amyloid fibril. Proc. Natl. Acad. Sci. U.S.A. 110, 5468-5473.

Forno, L.S. (1996). Neuropathology of Parkinson's disease. J. Neuropathol. Exp. Neurol. 55, 259-272.

Fujimoto, H., Higuchi, M., Koike, M., Ode, H., Pinak, M., Bunta, J.K., Nemoto, T., Sakudoh, T., Honda, N., Maekawa, H., et al. (2012). A possible overestimation of the effect of acetylation on lysine residues in KQ mutant analysis. J. Comput. Chem. 33, 239-246.

Gejyo, F., Yamada, T., Odani, S., Nakagawa, Y., Arakawa, M., Kunitomo, T., Kataoka, H., Suzuki, M., Hirasawa, Y., Shirahama, T., and et al. (1985). A new form of amyloid protein associated with chronic hemodialysis was identified as $\beta 2$-microglobulin. Biochem. Biophys. Res. Commun. 129, 701-706.

Ghari, F., Quirke, A.M., Munro, S., Kawalkowska, J., Picaud, S., McGouran, J., Subramanian, V., Muth, A., Williams, R., Kessler, B., et al. (2016). Citrullination-acetylation interplay guides E2F-1 activity during the inflammatory response. Sci. Adv. 2, e1501257.

Gidalevitz, T., Prahlad, V., and Morimoto, R.I. (2011). The stress of protein misfolding: from single cells to multicellular organisms. Cold Spring Harb. Perspect. Biol. 3.

Graham, R.K., Deng, Y., Slow, E.J., Haigh, B., Bissada, N., Lu, G., Pearson, J., Shehadeh, J., Bertram, L., Murphy, Z., et al. (2006). Cleavage at the caspase- 6 site is required for neuronal dysfunction and degeneration due to mutant huntingtin. Cell 125, 1179-1191.

Haj-Yahya, M. and Lashuel, H.A. (2018). Protein semisynthesis provides access to Tau disease-associated post-translational modifications (PTMs) and paves the way to deciphering the Tau PTM code in health and diseased states. J. Am. Chem. Soc. 140, 6611-6621.

Halle, A., Hornung, V., Petzold, G.C., Stewart, C.R., Monks, B.G., Reinheckel, T., Fitzgerald, K.A., Latz, E., Moore, K.J., and Golenbock, D.T. (2008). The NALP3 inflammasome is involved in the innate immune response to amyloid- $\beta$. Nat. Immunol. 9, 857-865.

Hanson, S.R., Culyba, E.K., Hsu, T.L., Wong, C.H., Kelly, J.W., and Powers, E.T. (2009). The core trisaccharide of an N-linked glycoprotein intrinsically accelerates folding and enhances stability. Proc. Natl. Acad. Sci. USA 106, 3131-3136.

Hartl, F.U. and Hayer-Hartl, M. (2009). Converging concepts of protein folding in vitro and in vivo. Nat. Struct. Mol. Biol. 16, 574-581.

Hartl, F.U., Bracher, A., and Hayer-Hartl, M. (2011). Molecular chaperones in protein folding and proteostasis. Nature 475 , 324-332.

Hemmingsen, S.M., Woolford, C., van der Vies, S.M., Tilly, K., Dennis, D.T., Georgopoulos, C.P., Hendrix, R.W., and Ellis, R.J. (1988). Homologous plant and bacterial proteins chaperone oligomeric protein assembly. Nature 333, 330-334.
Hickey, M.A. and Chesselet, M.F. (2003). Apoptosis in Huntington's disease. Prog. Neuropsychopharmacol. Biol. Psychiatry 27, 255-265.

Hinault, M.P., Ben-Zvi, A., and Goloubinoff, P. (2006). Chaperones and proteases: cellular fold-controlling factors of proteins in neurodegenerative diseases and aging. J. Mol. Neurosci. 30, 249-265.

Hiyama, H., Yokoi, M., Masutani, C., Sugasawa, K., Maekawa, T., Tanaka, K., Hoeijmakers, J.H., and Hanaoka, F. (1999). Interaction of hHR23 with S5a. The ubiquitin-like domain of hHR23 mediates interaction with S5a subunit of $26 \mathrm{~S}$ proteasome. J. Biol. Chem. 274, 28019-28025.

Homma, K., Suzuki, K., and Sugawara, H. (2011). The Autophagy Database: an all-inclusive information resource on autophagy that provides nourishment for research. Nucleic Acids Res. 39, D986-990.

Hong, D.P., Han, S., Fink, A.L., and Uversky, V.N. (2011). Characterization of the non-fibrillar alpha-synuclein oligomers. Protein Pept. Lett. 18, 230-240.

Huang, X. and Dixit, V.M. (2016). Drugging the undruggables: exploring the ubiquitin system for drug development. Cell Res. 26, 484-498.

Jackson, M.P. and Hewitt, E.W. (2017). Why are functional amyloids non-toxic in humans? Biomolecules 7.

Jahn, T.R. and Radford, S.E. (2005). The Yin and Yang of protein folding. FEBS J. 272, 5962-5970.

Johnston, J.A., Ward, C.L., and Kopito, R.R. (1998). Aggresomes: a cellular response to misfolded proteins. J. Cell Biol. 143, 1883-1898.

Kawaguchi, Y., Kovacs, J.J., McLaurin, A., Vance, J.M., Ito, A., and Yao, T.P. (2003). The deacetylase HDAC6 regulates aggresome formation and cell viability in response to misfolded protein stress. Cell 115, 727-738.

Kessler, B.M. and Edelmann, M.J. (2011). PTMs in conversation: activity and function of deubiquitinating enzymes regulated via posttranslational modifications. Cell Biochem. Biophys. 60, 21-38.

Klionsky, D.J. (2008). Autophagy revisited: a conversation with Christian de Duve. Autophagy 4, 740-743.

Knowles, T.P., Vendruscolo, M., and Dobson, C.M. (2014). The amyloid state and its association with protein misfolding diseases. Nat. Rev. Mol. Cell Biol. 15, 384-396.

Komander, D. and Rape, M. (2012). The ubiquitin code. Annu. Rev. Biochem. 81, 203-229.

Kyle, R.A. (2001). Amyloidosis: a convoluted story. Br. J. Haematol. 114, 529-538.

Lahortiga, I. and Cox, L. (2018). Library of Science and Medical Illustrations. Somersault 18:24. Cell Biology.

Lang, K. and Schmid, F.X. (1988). Protein-disulphide isomerase and prolyl isomerase act differently and independently as catalysts of protein folding. Nature 331, 453-455.

Lasagna-Reeves, C.A., Glabe, C.G., and Kayed, R. (2011). Amyloid- $\beta$ annular protofibrils evade fibrillar fate in Alzheimer disease brain. J. Biol. Chem. 286, 22122-22130.

Lashuel, H.A., Petre, B.M., Wall, J., Simon, M., Nowak, R.J., Walz, T., and Lansbury Jr, P.T. (2002). Alpha-synuclein, especially the Parkinson's disease-associated mutants, forms pore-like annular and tubular protofibrils. J. Mol. Biol. 322, 1089-1102.

Laskey, R.A., Honda, B.M., Mills, A.D., and Finch, J.T. (1978). Nucleosomes are assembled by an acidic protein which binds histones and transfers them to DNA. Nature 275, 416-420. 
Levine, B., Mizushima, N., and Virgin, H.W. (2011). Autophagy in immunity and inflammation. Nature 469, 323-335.

Levine, P.M., Galesic, A., Balana, A.T., Mahul-Mellier, A.L., Navarro, M.X., De Leon, C.A., Lashuel, H.A., and Pratt, M.R. (2019). $\alpha$-Synuclein O-GIcNAcylation alters aggregation and toxicity, revealing certain residues as potential inhibitors of Parkinson's disease. Proc. Natl. Acad. Sci. U.S.A. 116, 1511-1519.

Levinthal, C. (1969). How to Fold Graciously. Mossbauer Spectroscopy in Biological Systems: Proceedings of a meeting held at Allerton House (Monticello, IL: University of Illinois Press), 22-24.

Li, W., Bengtson, M.H., Ulbrich, A., Matsuda, A., Reddy, V.A., Orth, A., Chanda, S.K., Batalov, S., and Joazeiro, C.A. (2008). Genome-wide and functional annotation of human E3 ubiquitin ligases identifies MULAN, a mitochondrial E3 that regulates the organelle's dynamics and signaling. PLoS One 3, e1487.

Linke, R.P., Bommer, J., Ritz, E., Waldherr, R., and Eulitz, M. (1986). Amyloid kidney stones of uremic patients consist of $\beta 2$ microglobulin fragments. Biochem. Biophys. Res. Commun. 136, 665-671.

Lise, S. and Jones, D.T. (2005). Sequence patterns associated with disordered regions in proteins. Proteins 58, 144-150.

Lu, J. and Deutsch, C. (2005). Folding zones inside the ribosomal exit tunnel. Nat. Struct. Mol. Biol. 12, 1123-1129.

Maroteaux, L., Campanelli, J.T., and Scheller, R.H. (1988). Synuclein: a neuron-specific protein localized to the nucleus and presynaptic nerve terminal. J. Neurosci. 8, 2804-2815.

McNaught, K.S., Belizaire, R., Jenner, P., Olanow, C.W., and Isacson, O. (2002). Selective loss of $20 \mathrm{~S}$ proteasome alpha-subunits in the substantia nigra pars compacta in Parkinson's disease. Neurosci. Lett. 326, 155-158.

Meijer, A.J. and Codogno, P. (2004). Regulation and role of autophagy in mammalian cells. Int. J. Biochem. Cell Biol. 36, $2445-2462$.

Min, S.W., Chen, X., Tracy, T.E., Li, Y., Zhou, Y., Wang, C., Shirakawa, K., Minami, S.S., Defensor, E., Mok, S.A., et al. (2015). Critical role of acetylation in tau-mediated neurodegeneration and cognitive deficits. Nat. Med. 21, 1154-1162.

Mizushima, N. and Klionsky, D.J. (2007). Protein turnover via autophagy: implications for metabolism. Annu. Rev. Nutr. 27, 19-40.

Mizushima, N., Yamamoto, A., Hatano, M., Kobayashi, Y., Kabeya, Y., Suzuki, K., Tokuhisa, T., Ohsumi, Y., and Yoshimori, T. (2001). Dissection of autophagosome formation using Apg5-deficient mouse embryonic stem cells. J. Cell Biol. 152, 657-668.

Mondragon-Rodriguez, S., Perry, G., Luna-Munoz, J., AcevedoAquino, M.C., and Williams, S. (2014). Phosphorylation of tau protein at sites Ser(396-404) is one of the earliest events in Alzheimer's disease and Down syndrome. Neuropathol. Appl. Neurobiol. 40, 121-135.

Mortimore, G.E., Lardeux, B.R., and Adams, C.E. (1988). Regulation of microautophagy and basal protein turnover in rat liver. Effects of short-term starvation. J. Biol. Chem. 263, 2506-2512.

New, M., Olzscha, H., La Thangue, N.B. (2012). HDAC inhibitorbased therapies: can we interpret the code? Mol. Oncol. 6 , 637-656.

New, M., Olzscha, H., Liu, G., Khan, O., Stimson, L., McGouran, J., Kerr, D., Coutts, A., Kessler, B., Middleton, M., and La Thangue, N.B. (2013). A regulatory circuit that involves HR23B and HDAC6 governs the biological response to HDAC inhibitors. Cell Death Differ. 20, 1306-1316.

Nikoletopoulou, V., Papandreou, M.E., and Tavernarakis, N. (2015). Autophagy in the physiology and pathology of the central nervous system. Cell Death Differ. 22, 398-407.

Nissen, M.H., Roepstorff, P., Thim, L., Dunbar, B., and Fothergill, J.E. (1990). Limited proteolysis of beta 2-microglobulin at Lys-58 by complement component C1s. Eur. J. Biochem. 189, 423-429.

Nussinov, R., Tsai, C.J., Xin, F., and Radivojac, P. (2012). Allosteric post-translational modification codes. Trends Biochem. Sci. 37, 447-455.

Olanow, C.W., Perl, D.P., DeMartino, G.N., and McNaught, K.S. (2004). Lewy-body formation is an aggresome-related process: a hypothesis. Lancet Neurol. 3, 496-503.

Olteanu, A. and Pielak, G.J. (2004). Peroxidative aggregation of alpha-synuclein requires tyrosines. Protein Sci. 13, 2852-2856.

Olzscha, H., Schermann, S.M., Woerner, A.C., Pinkert, S., Hecht, M.H., Tartaglia, G.G., Vendruscolo, M., Hayer-Hartl, M., Hartl, F.U., and Vabulas, R.M. (2011). Amyloid-like aggregates sequester numerous metastable proteins with essential cellular functions. Cell 144, 67-78.

Olzscha, H., New, M., and La Thangue, N.B. (2013). Personalised Cancer Medicine: Fulfilling the Promise. In: eLS. eLS (John Wiley \& Sons).

Olzscha, H., Sheikh, S., and La Thangue, N.B. (2015). Deacetylation of chromatin and gene expression regulation: a new target for epigenetic therapy. Crit. Rev. Oncog. 20, 1-17.

Olzscha, H., Bekheet, M.E., Sheikh, S., and La Thangue, N.B. (2016). HDAC Inhibitors. Methods Mol. Biol. 1436, 281-303.

Olzscha, H., Fedorov, O., Kessler, B.M., Knapp, S., and La Thangue, N.B. (2017). CBP/p300 bromodomains regulate amyloid-like protein aggregation upon aberrant lysine acetylation. Cell Chem. Biol. 24, 9-23.

Osaki, D. and Hiramatsu, H. (2016). Citrullination and deamidation affect aggregation properties of amyloid $\beta$-proteins. Amyloid 23, 234-241.

Ostermann, J., Horwich, A.L., Neupert, W., and Hartl, F.U. (1989). Protein folding in mitochondria requires complex formation with hsp60 and ATP hydrolysis. Nature 341, 125-130.

Pan, T., Kondo, S., Le, W., and Jankovic, J. (2008). The role of autophagy-lysosome pathway in neurodegeneration associated with Parkinson's disease. Brain 131, 1969-1978.

Pawar, A.P., Dubay, K.F., Zurdo, J., Chiti, F., Vendruscolo, M., and Dobson, C.M. (2005). Prediction of 'aggregation-prone' and 'aggregation-susceptible' regions in proteins associated with neurodegenerative diseases. J. Mol. Biol. 350, 379-392.

Pecho-Vrieseling, E., Rieker, C., Fuchs, S., Bleckmann, D., Esposito, M.S., Botta, P., Goldstein, C., Bernhard, M., Galimberti, I., Muller, M., et al. (2014). Transneuronal propagation of mutant huntingtin contributes to non-cell autonomous pathology in neurons. Nat. Neurosci. 17, 1064-1072.

Pickart, C.M. (2001). Mechanisms underlying ubiquitination. Annu. Rev. Biochem. 70, 503-533.

Prusiner, S.B. (1982). Novel proteinaceous infectious particles cause scrapie. Science 216, 136-144.

Relini, A., De Stefano, S., Torrassa, S., Cavalleri, O., Rolandi, R., Gliozzi, A., Giorgetti, S., Raimondi, S., Marchese, L., Verga, L., et al. (2008). Heparin strongly enhances the formation of $\beta 2$ microglobulin amyloid fibrils in the presence of type I collagen. J. Biol. Chem. 283, 4912-4920. 
Rombouts, Y., Willemze, A., van Beers, J.J., Shi, J., Kerkman, P.F., van Toorn, L., Janssen, G.M., Zaldumbide, A., Hoeben, R.C., Pruijn, G.J., et al. (2016). Extensive glycosylation of ACPA-IgG variable domains modulates binding to citrullinated antigens in rheumatoid arthritis. Ann. Rheum. Dis. 75, 578-585.

Rooman, M., Dehouck, Y., Kwasigroch, J.M., Biot, C., and Gilis, D. (2002). What is paradoxical about Levinthal paradox? J Biomol. Struct. Dyn. 20, 327-329.

Ross, C.A. and Pickart, C.M. (2004). The ubiquitin-proteasome pathway in Parkinson's disease and other neurodegenerative diseases. Trends Cell Biol. 14, 703-711.

Rudiger, S., Germeroth, L., Schneider-Mergener, J., and Bukau, B. (1997). Substrate specificity of the DnaK chaperone determined by screening cellulose-bound peptide libraries. EMBO J. 16, 1501-1507.

Ryan, M.T. and Hoogenraad, N.J. (2007). Mitochondrial-nuclear communications. Annu. Rev. Biochem. 76, 701-722.

Sakkas, L.I., Bogdanos, D.P., Katsiari, C., and Platsoucas, C.D. (2014). Anti-citrullinated peptides as autoantigens in rheumatoid arthritis-relevance to treatment. Autoimmun. Rev. 13, 1114-1120.

Saxton, R.A. and Sabatini, D.M. (2017). mTOR signaling in growth, metabolism, and disease. Cell 169, 361-371.

Sherman, M.Y. and Goldberg, A.L. (2001). Cellular defenses against unfolded proteins: a cell biologist thinks about neurodegenerative diseases. Neuron 29, 15-32.

Smith, B.C. and Denu, J.M. (2009). Chemical mechanisms of histone lysine and arginine modifications. Biochim. Biophys. Acta 1789, 45-57.

Smith, M.H., Ploegh, H.L., and Weissman, J.S. (2011). Road to ruin: targeting proteins for degradation in the endoplasmic reticulum. Science 334, 1086-1090.

Sodhi, C.P., Perez, R.G., and Gottardi-Littell, N.R. (2008). Phosphorylation of $\beta$-amyloid precursor protein (APP) cytoplasmic tail facilitates amyloidogenic processing during apoptosis. Brain Res. 1198, 204-212.

Spillantini, M.G., Schmidt, M.L., Lee, V.M., Trojanowski, J.Q., Jakes, R., and Goedert, M. (1997). Alpha-synuclein in Lewy bodies. Nature 388, 839-840.

Spurrier, J., Shukla, A.K., McLinden, K., Johnson, K., and Giniger, E. (2018). Altered expression of the Cdk5 activator-like protein, $\mathrm{Cdk} 5 \alpha$, causes neurodegeneration, in part by accelerating the rate of aging. Dis. Model Mech. 11.

Steiner, H., Fluhrer, R., and Haass, C. (2008). Intramembrane proteolysis by $\gamma$-secretase. J. Biol. Chem. 283, 29627-29631.

Sunde, M., Serpell, L.C., Bartlam, M., Fraser, P.E., Pepys, M.B., and Blake, C.C. (1997). Common core structure of amyloid fibrils by synchrotron X-ray diffraction. J. Mol. Biol. 273, 729-739.

Tabas, I. and Ron, D. (2011). Integrating the mechanisms of apoptosis induced by endoplasmic reticulum stress. Nat. Cell Biol. 13, 184-190.

Tanikawa, C., Ueda, K., Suzuki, A., lida, A., Nakamura, R., Atsuta, N., Tohnai, G., Sobue, G., Saichi, N., Momozawa, Y., et al. (2018). Citrullination of RGG motifs in FET proteins by PAD4 regulates protein aggregation and ALS susceptibility. Cell Rep. 22, 1473-1483.

Tofaris, G.K., Razzaq, A., Ghetti, B., Lilley, K.S., and Spillantini, M.G. (2003). Ubiquitination of $\alpha$-synuclein in Lewy bodies is a pathological event not associated with impairment of proteasome function. J. Biol. Chem. 278, 44405-44411.
Tsukada, M. and Ohsumi, Y. (1993). Isolation and characterization of autophagy-defective mutants of Saccharomyces cerevisiae. FEBS Lett. 333, 169-174.

Uemura, E., Niwa, T., Minami, S., Takemoto, K., Fukuchi, S., Machida, K., Imataka, H., Ueda, T., Ota, M., and Taguchi, H. (2018). Large-scale aggregation analysis of eukaryotic proteins reveals an involvement of intrinsically disordered regions in protein folding. Sci. Rep. 8, 678.

Utsumi, T., Sato, M., Nakano, K., Takemura, D., Iwata, H., and Ishisaka, R. (2001). Amino acid residue penultimate to the aminoterminal gly residue strongly affects two cotranslational protein modifications, $\mathrm{N}$-myristoylation and $\mathrm{N}$-acetylation. J. Biol. Chem. 276, 10505-10513.

Uversky, V.N. and Dunker, A.K. (2010). Understanding protein non-folding. Biochim. Biophys. Acta 1804, 1231-1264.

Van Damme, P., Hole, K., Pimenta-Marques, A., Helsens, K., Vandekerckhove, J., Martinho, R.G., Gevaert, K., and Arnesen, T. (2011). NatF contributes to an evolutionary shift in protein $\mathrm{N}$-terminal acetylation and is important for normal chromosome segregation. PLoS Genet. 7, e1002169.

van den Berg, B., Ellis, R.J., and Dobson, C.M. (1999). Effects of macromolecular crowding on protein folding and aggregation. EMBO J. 18, 6927-6933.

van der Helm-van Mil, A.H., Verpoort, K.N., Breedveld, F.C., Huizinga, T.W., Toes, R.E., and de Vries, R.R. (2006). The HLA-DRB1 shared epitope alleles are primarily a risk factor for anti-cyclic citrullinated peptide antibodies and are not an independent risk factor for development of rheumatoid arthritis. Arthritis Rheum. 54, 1117-1121.

Vembar, S.S. and Brodsky, J.L. (2008). One step at a time: endoplasmic reticulum-associated degradation. Nat. Rev. Mol. Cell Biol. 9, 944-957.

Vijay-Kumar, S., Bugg, C.E., and Cook, W.J. (1987). Structure of ubiquitin refined at $1.8 \AA$ A resolution. J. Mol. Biol. 194, 531-544.

Vilchez, D., Saez, I., and Dillin, A. (2014). The role of protein clearance mechanisms in organismal ageing and age-related diseases. Nat. Commun. 5, 5659.

Walker, F.O. (2007). Huntington's disease. Lancet 369, 218-228.

Wang, Q., Zhang, Y., Yang, C., Xiong, H., Lin, Y., Yao, J., Li, H., Xie, L., Zhao, W., Yao, Y., et al. (2010). Acetylation of metabolic enzymes coordinates carbon source utilization and metabolic flux. Science 327, 1004-1007.

Wang, Y., Yang, R., Gu, J., Yin, X., Jin, N., Xie, S., Wang, Y., Chang, H., Qian, W., Shi, J., et al. (2015). Cross talk between PI3K-AKT-GSK$3 \beta$ and PP2A pathways determines tau hyperphosphorylation. Neurobiol. Aging 36, 188-200.

Wegner, N., Lundberg, K., Kinloch, A., Fisher, B., Malmstrom, V., Feldmann, M., and Venables, P.J. (2010). Autoimmunity to specific citrullinated proteins gives the first clues to the etiology of rheumatoid arthritis. Immunol. Rev. 233, 34-54.

Weingarten, M.D., Lockwood, A.H., Hwo, S.Y., and Kirschner, M.W. (1975). A protein factor essential for microtubule assembly. Proc. Natl. Acad Sci. U.S.A. 72, 1858-1862.

Woerner, A.C., Frottin, F., Hornburg, D., Feng, L.R., Meissner, F., Patra, M., Tatzelt, J., Mann, M., Winklhofer, K.F., Hartl, F.U., et al. (2016). Cytoplasmic protein aggregates interfere with nucleocytoplasmic transport of protein and RNA. Science 351, 173-176. 
Wright, P.E. and Dyson, H.J. (2015). Intrinsically disordered proteins in cellular signalling and regulation. Nat. Rev. Mol. Cell Biol. 16, 18-29.

Wu, J.W., Hussaini, S.A., Bastille, I.M., Rodriguez, G.A., Mrejeru, A., Rilett, K., Sanders, D.W., Cook, C., Fu, H., Boonen, R.A., et al. (2016). Neuronal activity enhances tau propagation and tau pathology in vivo. Nat. Neurosci. 19, 1085-1092.

Xie, H., Vucetic, S., lakoucheva, L.M., Oldfield, C.J., Dunker, A.K., Obradovic, Z., and Uversky, V.N. (2007). Functional anthology of intrinsic disorder. 3. Ligands, post-translational modifications, and diseases associated with intrinsically disordered proteins. J. Proteome Res. 6, 1917-1932.

Xu, H., Zhou, J., Lin, S., Deng, W., Zhang, Y., and Xue, Y. (2017). PLMD: An updated data resource of protein lysine modifications. J. Genet. Genomics 44, 243-250.

Yamamoto, A. and Yue, Z. (2014). Autophagy and its normal and pathogenic states in the brain. Annu. Rev. Neurosci. 37, 55-78.

Yi, C.W., Wang, L.Q., Huang, J.J., Pan, K., Chen, J., and Liang, Y. (2018). Glycosylation significantly inhibits the aggregation of human prion protein and decreases its cytotoxicity. Sci. Rep. 8, 12603.

Zhang, G. and Ignatova, Z. (2011). Folding at the birth of the nascent chain: coordinating translation with co-translational folding. Curr. Opin. Struct. Biol. 21, 25-31.

Zhang, X. and Qian, S.B. (2011). Chaperone-mediated hierarchical control in targeting misfolded proteins to aggresomes. Mol. Biol. Cell 22, 3277-3288.

Zhang, G., Hubalewska, M., and Ignatova, Z. (2009). Transient ribosomal attenuation coordinates protein synthesis and cotranslational folding. Nat. Struct. Mol. Biol. 16, 274-280.

Zhu, S., Shala, A., Bezginov, A., Sljoka, A., Audette, G., and Wilson, D.J. (2015). Hyperphosphorylation of intrinsically disordered tau protein induces an amyloidogenic shift in its conformational ensemble. PLoS One 10, e0120416.

\section{Bionote}

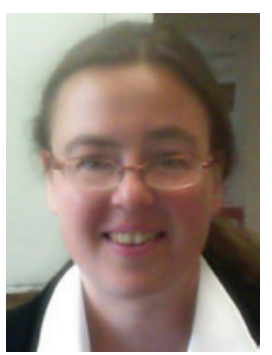

Heidi Olzscha

Institut für Physiologische Chemie, Medizinische Fakultät, Martin-LutherUniversität Halle-Wittenberg, Hollystr. 1, D-06114 Halle/Saale, Germany, Heidi.Olzscha@medizin.uni-halle.de. https://orcid.org/0000-0002-1929-1384

Heidi Olzscha studied Biochemistry and Molecular Biology at the University of Hamburg and wrote her Diploma thesis in tumour biology about the receptor tyrosine kinase FLT3 at the University Hospital Hamburg-Eppendorf, Institute of Clinical Chemistry under supervision of Prof. Christoph Wagener. She then did her graduate studies in protein folding, misfolding and proteostasis for a PhD in Biochemistry at the Max Planck Institute of Biochemistry in Martinsried under supervision of Prof. F.-Ulrich Hartl, focussing on protein misfolding in neurodegenerative diseases. She pursued postdoctoral studies at the University of Oxford in the Department of Oncology as an EMBO long-term fellow. Her research focussed there mainly on posttranslational modifications in various aspects of protein quality control and cancer. She became a member of the Senior Common Room at Somerville College, a Fulford Junior Research Fellow in Medicine and was awarded a Celgene Fellowship. She has now a PI position at the Institute of Physiological Chemistry, Medical Faculty, of the Martin-Luther-University Halle-Wittenberg, working on how posttranslational modifications impact on protein quality control and proteinopathies. 